Moreno Alcaide, M., Román Punzón, J.M. y Ruiz Montes, P. (2019): “El uso de tubi fittili para cubiertas abovedadas en la Hispania romana. Revisión bibliográfica y estado de la

cuestión", Spal 28.1: 131-156.

DOI: http://dx.doi.org/10.12795/spal.2019.i28.06

\title{
EL USO DE TUBI FITTILI PARA CUBIERTAS ABOVEDADAS EN LA HISPANIA ROMANA. REVISIÓN BIBLIOGRÁFICA Y ESTADO DE LA CUESTIÓN
}

\section{THE USE OF TUBI FITTILI FOR VAULTING ROOF IN ROMAN HISPANIA. BIBLIOGRAPHICAL REVIEW AND STATUS OF THE ISSUE}

\author{
MANUEL MORENO ALCAIDE \\ Universidad de Granada. Dpto. Prehistoria y Arqueología. Facultad de Filosofía y Letras. \\ Campus de Cartuja s/n. Universidad de Granada. Correo-e: manuelma@ugr.es \\ University of Cambridge. Faculty of Classics. Cambridge University. Correo-e: mm2221@cam.ac.uk \\ JULIO M. ROMÁN PUNZÓN \\ Universidad de Granada. Dpto. Historia Medieval y CCTTHH. Facultad de Filosofía y Letras. \\ Campus de Cartuja s/n. Universidad de Granada. Correo-e: romanp@ugr.es \\ PABLO RUIZ MONTES \\ Universidad de Granada. Dpto. Prehistoria y Arqueología. Facultad de Filosofía y Letras. \\ Campus de Cartuja s/n. Universidad de Granada. Correo-e: prmontes@ugr.es
}

Resumen: El hallazgo de numerosas piezas cerámicas, conocidas como tubi fittili, en la villa romana de Salar nos ha permitido realizar un análisis de los casos conocidos en Hispania del uso de este tipo de material cerámico en la construcción de cubiertas abovedadas, poniendo de relieve los errores cometidos en su identificación, la escasez de casos fehacientes documentados en Hispania, así como la peculiar concentración de estas piezas en villas del entorno de la Vega de Granada.

Palabras clave: tubi fittili, sistema constructivo, arquitectura, Antigüedad tardía hispanorromana.

\section{INTRODUCCIÓN}

Las técnicas y materiales empleados en la construcción durante la época romana fueron muy diversas, destacando por su carácter innovador y por la variabilidad de las soluciones empleadas. Probablemente sea en la construcción de bóvedas y cubiertas curvas
Abstract: The discovery of numerous terracotta vaulting tubes (tubi fittili) in the Roman villa of Salar has allowed us to carry out an analysis of the known cases in Spain of the use of this type of material in the vaulted ceiling, highlighting the mistakes made in their identification, the scarcity of documented cases in Hispania, as well as the peculiar concentration of these pieces in villae around the Vega de Granada.

Keywords: terracotta vaulting tubes, construction system, architecture, Late Antiquity, Roman Hispania

donde demostraron un mayor ingenio. De entre las distintas opciones empleadas, en este trabajo recogemos la aparición y uso de la construcción de bóvedas con tubos cerámicos (tubi fittili) en la arquitectura hispanorromana. Los principales trabajos, de carácter general, sobre la construcción con tubos cerámicos han sido llevados a cabo por Wilson (1992: 97-129) y Storz 
(1994), que más tarde se verían ampliados con los estudios de Lancaster (2012: 145-160; 2015: 99-128). Estas obras recogen trabajos previos (Monneret de Vilard 1924: 149-154; Arslan 1965: 45-52; Tomasello 2005: 145-155), así como resultados de investigaciones en los principales yacimientos donde se ha documentado el uso de tubi fittili, con diferentes cronologías y ubicaciones, entre los que destacan las termas romanas de Florencia (Shepherd 2014: 257-265), Caesarea Maritima (Vann 1993: 29-34), Punta del Fenaio en la Isla del Giglio (Bound 1997: 187-200), Sabratha (Dodge 1989: 249-251), Bulla Regia (Lézine 1954: 168-181), Chester, UK (Mason 1990: 215-222), fuerte romano de Chesters, UK (Wilson 2002: 180-185), Rávena (Bovini 1960: 78-99), San Vital de Rávena (Russo 1996: 285-329), Pompeya (Scurati-Manzoni 1997: 9-18) e Italia entre los siglos V y VI d.C. (Verzone 1938: 7-12).

Frente a la abundante bibliografía sobre el origen de esta técnica constructiva en el siglo III a.C., en Morgantina (Sicilia), hasta su difusión tardía en el siglo III d.C., en el norte de África, el empleo de tubos cerámicos para la construcción de bóvedas en el ámbito hispanorromano pasó desapercibido en los primeros estudios que profundizaban en la edificación de esta tipología de cubiertas en el Mediterráneo (Wilson 1992: 114, fig. 19, 118). Los primeros ejemplos hispanos fueron evidenciados por Storz (1994: 88), localizados en la villa romana de Els Munts (Altafulla), en Tarragona, y en los museos de Sagunto y Mérida. Sin embargo, la relación más completa, hasta el momento, sobre el empleo de tubos cerámicos en la construcción de bóvedas ha sido realizado por Lancaster, quien aporta un mapa de su distribución que abarca todo el ámbito mediterráneo (Lancaster 2015: 101, fig. 66). Para Hispania, identifica cinco nuevos enclaves que vienen a completar los cinco aportados por Storz; estos son: Vilar de Santos (Ourense), Cercadilla (Córdoba), la villa de los Vergeles (Granada), la Casa de Hippolytus (Complutum) y las termas republicanas de Cabrera de Mar. No obstante, debemos reconocer que la mayoría de los nuevos ejemplos citados por Lancaster vienen recogidos en un artículo previo de Torrecilla (1999: 408-409).

Ante la aparición de un nuevo ejemplo de su utilización en la villa romana de Salar (Granada), hemos creído necesario realizar una completa revisión de las evidencias actualmente documentadas en la península ibérica, con el objetivo de generar un marco común donde todos los datos sean valorados desde los mismos parámetros, para así poder confirmar o descartar el uso de este sistema de cubierta de edificaciones en los casos expuestos y conocidos actualmente. Al elenco anterior añadiremos los ejemplos de la villa romana de Rabaçal (Penela, Portugal), la de Casas de Luján (Cuenca) y la de Gabia la Grande (Granada) y Daragoleja (Granada), que no habían sido analizados en trabajos anteriores.

\section{CUESTIONES PREVIAS Y PROBLEMÁTICA PARA SU NOMENCLATURA E IDENTIFICACIÓN}

Rastrear la utilización de este tipo de producciones cerámicas para la realización de cubiertas curvas, tanto en forma de bóveda como de cúpula, en contextos primarios arqueológicos de la península ibérica se convierte en una tarea harto complicada. Varias son las causas que provocan dicha dificultad. Así, el primer problema que debemos afrontar al abordar su estudio es la diversa y variada nomenclatura existente para designar esta tipología cerámica. El término más extendido en la bibliografía específica proviene del italiano tubi fittili, cuya traducción más próxima al castellano es "tubo de barro o arcilla". En el ámbito internacional, las denominaciones acuñadas son las siguientes: en inglés, terracotta vaulting tubes; en alemán, tonröhren; y en francés, tubes emboîtés; todas ellas, alusivas al empleo de tubos de cerámica huecos para la construcción de bóvedas. En este sentido, Lancaster (2015: 213, n. 1) propone el uso en castellano de "tubo afusado", denominación que ya había sido utilizada previamente en publicaciones en español; sin embargo, el término afusado ("de forma de huso"), no solo no se encuentra recogido en el actual Diccionario de la Real Academia Española (23 ${ }^{\text {a }}$ versión, 2014), siendo un uso obsoleto del castellano, sino que ni siquiera se corresponde con la forma real de estos tubos. Por tanto, nos decantamos por la denominación de tubos de cerámica para la construcción de bóvedas, asimilando su definición con $t u b i$ fittili y terracotta vaulting tubes.

Por otro lado, la utilización de tubos cerámicos no fue exclusiva de la construcción de bóvedas; de hecho, entre sus principales aplicaciones, se contarían la conducción de agua o la circulación de aire caliente en hornos o en sistemas de calefacción. Por ello, al designar bajo la nomenclatura "tubo" a tipos formal y funcionalmente distintos, puede generarse una gran confusión si no se especifica su contexto primario. La principal característica que podemos establecer para diferenciarlos es que, por regla general, tanto los tubos utilizados en la cámara de cocción de los hornos como los documentados en el interior de las paredes de las salas calefactadas, deben estar abiertos por ambos extremos para 


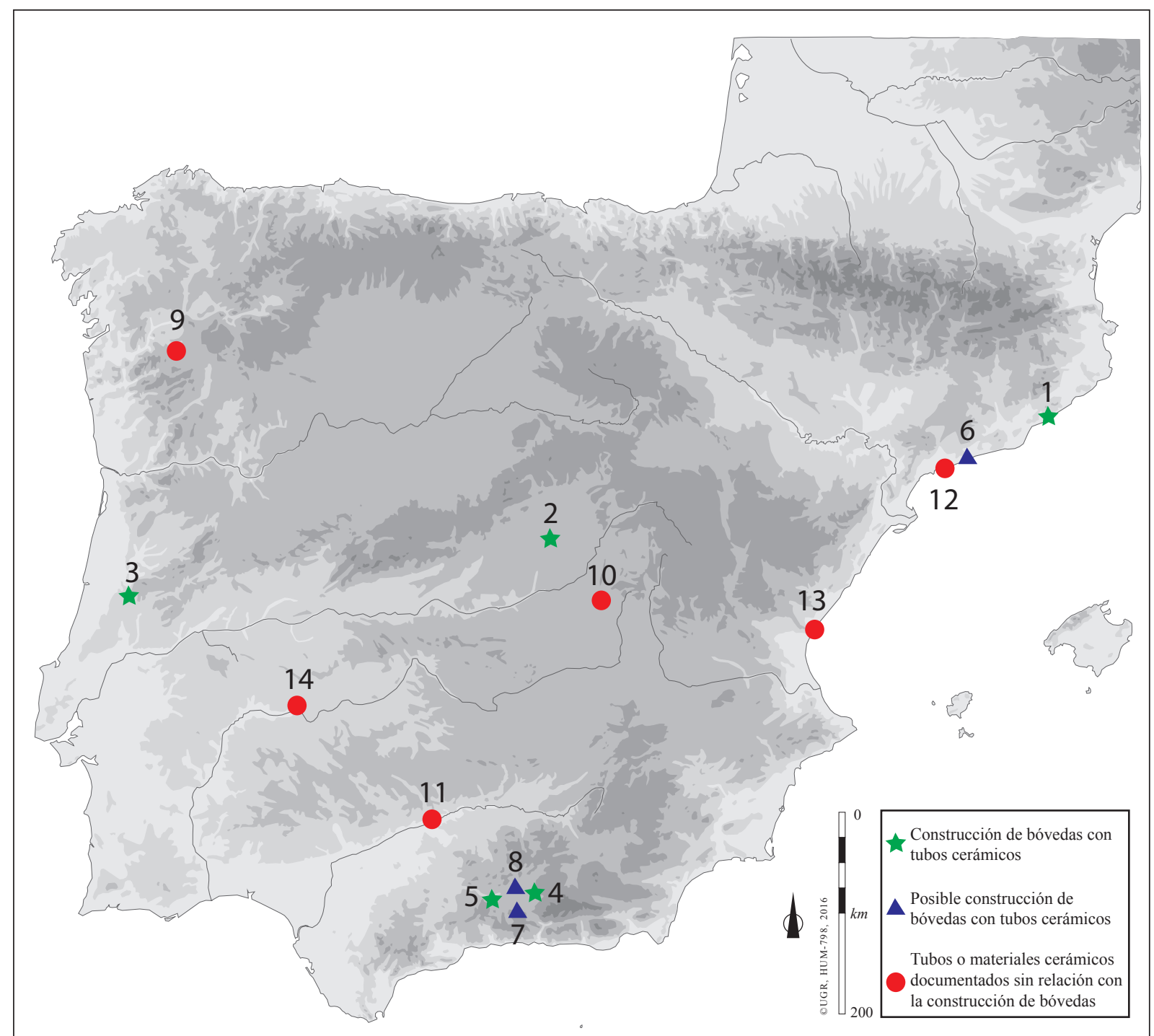

Figura 1. Mapa de distribución de los tubos cerámicos para la construcción de bóvedas en Hispania. 1. Cabrera de Mar (Barcelona). 2. Casa de Hippolytus, Complutum (Alcalá de Henares, Madrid). 3. Villa romana de Rabaçal (Penela, Coimbra). 4. Villa romana de los Vergeles (Granada). 5. Villa romana de Salar (Salar, Granada). 6. Villa dels Munts (Altafulla, Tarragona). 7. Villa romana de Las Gabias (Gabia la Grande, Granada). 8. Villa romana de Daragoleja (Pinos Puente, Granada). 9. Vilar de Santos (Orense).

10. Villa de Casas de Luján, (Saelices, Cuenca). 11. Cercadilla (Córdoba). 12. Tarragona. 13. Sagunto. 14. Mérida.

permitir el paso del calor. Por tanto, pese a estar conectados entre sí, su extremo apuntado debe estar abierto; mientras en los tubos empleados en las bóvedas, uno de los extremos, el apuntado, suele estar cerrado, y de estar abierto, queda taponado al realizar su ensamblaje, ya que se realiza con algún tipo de mortero o yeso, para fraguar su unión. Por otro lado, y como se ha demostrado con la arqueología experimental (Storz 1994), se necesitan cientos de tubos, si no miles, para poder construir una bóveda que abarque un área de tamaño pequeño o mediano, por lo que no podemos estar seguros de su utilización como sistema de cubierta cuando tan solo se documentan de forma aislada o esporádica y descontextualizados. Sin embargo, este problema es difícil de solventar, más cuando en su mayoría no son recogidos durante la excavación, y ni siquiera contados o medidos.

Por tanto, pese a estas indicaciones, somos conscientes de la dificultad objetiva existente para la identificación del uso de tubos cerámicos en la construcción 
de bóvedas, especialmente si no se trata de contextos arqueológicos bien documentados, por lo que se hace necesario un análisis detallado de cada uno de los casos.

\section{LAS BÓVEDAS CONSTRUIDAS CON TUBOS CERÁMICOS EN HISPANIA}

La técnica edilicia de construcción de espacios abovedados utilizando tubos cerámicos debió de ser un fenómeno de una escasa repercusión en la península ibérica, a tenor de los datos aquí recogidos y del estado actual de la investigación para la arquitectura hispanorromana (fig. 1). De los 14 ejemplos conocidos y publicados de su empleo, en tan solo cinco casos tenemos las suficientes evidencias arqueológicas para corroborar su utilización en la realización de cubiertas abovedadas, documentándose mediante excavaciones arqueológicas en contextos de derrumbe de las salas que cubrían (1. Cabrera de Mar, 2 Casa de Hippolytus, 3. Villa romana de Rabaçal, 4. Villa romana de los Vergeles, 5. Villa romana de Salar). A estos podríamos sumar la villa romana de Els Munts (6), cuya descripción del derrumbe de la techumbre del frigidarium se aproxima bastante a la técnica aquí descrita; sin embargo, la antigüedad de su excavación, unido a los problemas estratigráficos que presenta y a la existencia de publicaciones que plantean hipótesis diferentes de cubierta, nos impide afirmar de forma categórica su empleo. La misma situación es extensible a la villa romana de Daragoleja (8), donde es imposible testimoniar su uso ante la falta de evidencias y datos que corroboren la descripción de sus excavadores, situación similar a la villa romana de Las Gabias (7).

Los criterios seleccionados para su estudio vienen determinados por diversos aspectos: en primer lugar, si las referencias que poseemos hacen mención a tubos cerámicos documentados in situ, es decir, si su lugar de procedencia es parte del derrumbe de las estancias que cubrían, o si, por el contrario, las piezas están descontextualizadas; en segundo lugar, el número de tubos que se han registrado, ya que sabemos que era necesario un gran número de ellos para realizar los cerramientos y por tanto, un solo tubo o un número poco elevado no pueden garantizar que se trate del derrumbe de una bóveda; sin embargo, esta premisa plantea el problema de que, en muchos casos, estas piezas no eran recogidas, ni siquiera documentadas, por lo que no es un requisito categórico; finalmente, en función de su tipología, ya que los tubos cerámicos empleados en bóvedas tienen forma de botella, abierta por su base y con el otro extremo apuntado y cerrado, además de presentar su ensamblado con mortero para asegurar la unión entre las distintas piezas cerámicas que conforman cada hilera de tubos.

A partir de los datos analizados, presentamos una actualización de la distribución de bóvedas construidas con tubos cerámicos en Hispania, rechazando aquellos donde las evidencias no permiten su confirmación (tab. 1).

\subsection{Tubi fittili identificados en la construcción de bóvedas en registros in situ}

\subsubsection{Termas republicanas de Cabrera de Mar}

El testimonio más antiguo documentado en la península ibérica de construcción de una bóveda o cúpula con tubos cerámicos lo encontramos en las termas republicanas de Ca l'Arnau (Cabrera de Mar, Barcelona). Nos situamos en un excepcional contexto termal debido, por un lado, a la antigüedad de su construcción, datada en la segunda mitad del siglo II a.C.; y por otro, por la novedad de la inclusión de esta técnica edilicia en la península ibérica. El complejo termal de Ca l'Arnau forma parte de un asentamiento tardo-republicano cuya ocupación arrancaría a mediados del siglo II a.C., produciéndose su abandono en el primer cuarto del siglo I a.C. (Sinner y Ferrer 2016: 195). Las evidencias de este asentamiento republicano han sido identificadas con la antigua Ilduro (Ilturo).

Las termas de Cabrera de Mar fueron excavadas entre los años 1997 y 1998 (Martín 2000: 157-162). De entre sus salas, debemos destacar el caldarium y el tepidarium por ser en ellas donde se documentó la caída de su cubierta, formada por tres tipos diferentes de tubos cerámicos. Según su excavador, el tepidarium estaría cubierto por una cúpula, mientras el caldarium y el alveus lo estarían con una bóveda de cañón. El conjunto estructural que conforma la techumbre presentaría un grosor de, aproximadamente, $20-22 \mathrm{~cm}$, teniendo en cuenta el propio tamaño de los tubos, a los que se añade una capa de mortero de cal y arena de $5 \mathrm{~cm}$ en el extradós y de 3 $\mathrm{cm}$ en el intradós, que a su vez, estaban recubiertos con estuco blanco. Estos sistemas se combinan con cubiertas más tradicionales de tegulae sustentadas por un armazón de madera (apodyterium) (Martín 2000: 159-160).

Respecto a la tipología de los tubos cerámicos, hechos a torno, se han documentado tres tipos diferentes: uno, abierto por ambos extremos, que cumpliría la 
Tabla 1. Tubi fittili para la construcción de bóvedas documentados en Hispania.

\begin{tabular}{|c|c|c|c|c|c|c|}
\hline \multicolumn{7}{|c|}{ Tubi fittili identificados en la construcción de bóvedas en registros in situ } \\
\hline $\mathrm{N}^{\mathrm{o}}$ & Procedencia & $\begin{array}{l}\text { Edificio } \\
\text { Estancia }\end{array}$ & Cubierta & Medidas tubos & Cronología & Bibliografía \\
\hline 1 & $\begin{array}{l}\text { Cabrera de Mar } \\
\text { (Barcelona) }\end{array}$ & $\begin{array}{l}\text { Termas: } \\
\text { Tepidarium } \\
\text { Caldarium }\end{array}$ & $\begin{array}{l}\text { Cúpula } \\
\text { Bóveda de } \\
\text { cañón y } \\
\text { media cúpula }\end{array}$ & $\begin{array}{l}\text { Longitud } 20-22 \mathrm{~cm} \\
\text { Diámetro } 11 \mathrm{~cm} \\
\text { Unidos con barras de } \\
\text { hierro y trabados con } \\
\text { mortero }\end{array}$ & $\begin{array}{l}\text { Mitad s. II } \\
\text { a.C. }\end{array}$ & $\begin{array}{l}\text { Martín, 2000: 157-162. } \\
\text { Lancaster, 2015: 102- } \\
105 . \\
\text { Sinner y Ferrer, 2016: } \\
\text { 209, 215, 219, fig. 9, } \\
\text { fig. } 13 .\end{array}$ \\
\hline 2 & $\begin{array}{l}\text { Casa de } \\
\text { Hippolytus } \\
\text { Complutum } \\
\text { (Alcalá de } \\
\text { Henares, } \\
\text { Madrid) }\end{array}$ & $\begin{array}{l}\text { Sede de un } \\
\text { collegium } \\
\text { Sala de paso } \\
\text { próxima al } \\
\text { frigidarium }\end{array}$ & $\begin{array}{l}\text { Bóveda } \\
\text { 3'50 x } 7 \mathrm{~m}\end{array}$ & $\begin{array}{l}\text { Oscilan entre los } 26 \\
\mathrm{~cm} \text { y los } 18,6 \mathrm{~cm} \text { de } \\
\text { altura, un diámetro } \\
\text { máximo entre } 10,6 \mathrm{~cm} \\
\text { y } 7,6 \mathrm{~cm} \text { y un grosor } \\
\text { de las paredes entre } \\
7,2 \mathrm{~cm} \text { y } 0,6 \mathrm{~cm} .\end{array}$ & $\begin{array}{l}\text { Finales del } \\
\text { s. III d.C. } \\
\text { Fase III }\end{array}$ & $\begin{array}{l}\text { Rascón Marqués, 1998: } \\
208 . \\
\text { Rascón Marqués, 2007: } \\
\text { fig. } 14 .\end{array}$ \\
\hline 3 & $\begin{array}{l}\text { Villa romana de } \\
\text { Rabaçal (Penela, } \\
\text { Coímbra) }\end{array}$ & $\begin{array}{l}\text { Sala de planta de } \\
\text { cruz griega con } \\
\text { ábsides. } \\
\text { Área del balneario }\end{array}$ & - & $\begin{array}{l}\text { Entre } 17,5 \mathrm{~cm}, \text { y } 15,5 \\
\mathrm{~cm}, 13,5 \mathrm{~cm} \text { y } 9 \mathrm{~cm} \text { de } \\
\text { altura, con un diámetro } \\
\text { de } 6,5 \mathrm{~cm}\end{array}$ & s. IV-V d.C. & Pessoa 2004: 116 \\
\hline 4 & $\begin{array}{l}\text { Villa romana } \\
\text { de los Vergeles } \\
\text { (Granada) }\end{array}$ & $\begin{array}{l}\text { Sala } 1 . \\
\text { Dimensiones de la } \\
\text { sala: } 11,5 \text { x } 4,90 \mathrm{~m} \\
\text { terminada en una } \\
\text { cabecera absidial. } \\
\text { Triclinium. } \\
\text { Sobre los tubos } \\
\text { se documentó } \\
\text { un derrumbe de } \\
\text { tegulae }\end{array}$ & $\begin{array}{l}\text { Cubierta } \\
\text { abovedada }\end{array}$ & $\begin{array}{l}22 \mathrm{~cm} \text { de longitud y } 6 \\
\mathrm{~cm} \text { de diámetro. } \\
\text { Engarzados en hasta } 3 \\
\text { bandas }\end{array}$ & $\begin{array}{l}\text { Desde s. I al } \\
\text { s. IV-V d.C. }\end{array}$ & $\begin{array}{l}\text { Fresneda Padilla et al., } \\
\text { 1993: } 151 \text {, foto } 3 .\end{array}$ \\
\hline 5 & $\begin{array}{l}\text { Villa romana de } \\
\text { Salar } \\
\text { (Salar, Granada) }\end{array}$ & $\begin{array}{l}\text { Sector } 3 \\
\text { Ninfeo }\end{array}$ & $\begin{array}{l}\text { Cubierta } \\
\text { abovedada } \\
\text { Semibóveda }\end{array}$ & $\begin{array}{l}16 \mathrm{~cm} \text { de longitud por } \\
7-7,5 \mathrm{~cm} \text { de diámetro } \\
14,5-16 \mathrm{~cm} \text { de } \\
\text { longitud por } 6-6,5 \mathrm{~cm} \\
\text { de diámetro }\end{array}$ & $\begin{array}{l}\text { Siglos III-VI } \\
\text { d.C. }\end{array}$ & $\begin{array}{l}\text { Moreno Alcaide et al., } \\
2017 .\end{array}$ \\
\hline \multicolumn{7}{|c|}{ Tubi fittili de difícil adscripción para la construcción de bóvedas a partir de descripciones } \\
\hline 6 & $\begin{array}{l}\text { Villa dels Munts } \\
\text { (Altafulla, } \\
\text { Tarragona) }\end{array}$ & $\begin{array}{l}\text { Termas del Sur } \\
\text { Frigidarium }\end{array}$ & Bóveda & - & $\begin{array}{l}\text { Segunda } \\
\text { mitad } \\
\text { s. III d.C. }\end{array}$ & $\begin{array}{l}\text { Berges Soriano, } 1977 . \\
\text { López, 1993: } 64 . \\
\text { Otiña Hermoso, } 2005 .\end{array}$ \\
\hline 7 & $\begin{array}{l}\text { Villa romana de } \\
\text { Las Gabias } \\
\text { (Gabia la } \\
\text { Grande, } \\
\text { Granada) }\end{array}$ & - & - & $15 \mathrm{~cm}$ de longitud & $\begin{array}{l}\text { Desde el } \\
\text { siglo I-IV } \\
\text { d.C. }\end{array}$ & Cabré Aguiló, 1923: 11 \\
\hline 8 & $\begin{array}{l}\text { Villa romana } \\
\text { de Daragoleja } \\
\text { (Pinos Puente, } \\
\text { Granada) }\end{array}$ & - & - & - & $\begin{array}{l}\text { Siglos IV-V } \\
\text { d.C. }\end{array}$ & $\begin{array}{l}\text { Oliver y Gómez, } \\
1870 . \\
\text { Marín Díaz, 2016: } \\
63-264 \text {. }\end{array}$ \\
\hline
\end{tabular}




\begin{tabular}{|c|c|c|c|c|c|c|}
\hline \multicolumn{7}{|c|}{ Tubi fittili identificados en la construcción de bóvedas en registros in situ } \\
\hline $\mathrm{N}^{\mathrm{o}}$ & Procedencia & $\begin{array}{l}\text { Edificio } \\
\text { Estancia }\end{array}$ & Cubierta & Medidas tubos & Cronología & Bibliografía \\
\hline \multicolumn{7}{|c|}{ Tubi fittili descartados para la construcción de bóvedas } \\
\hline 9 & $\begin{array}{l}\text { Vilar de Santos } \\
\text { (Orense) }\end{array}$ & - & - & $\begin{array}{l}\text { No existen fotos ni } \\
\text { descripciones solo una breve } \\
\text { referencia a } 50 \text { vasijas unida } \\
\text { dos a dos, con } 22 \mathrm{~cm} \text { de } \\
\text { longitud }\end{array}$ & $\begin{array}{l}\text { Sin } \\
\text { contexto }\end{array}$ & $\begin{array}{l}\text { López Cuevillas, } \\
\text { 1953: } 437 . \\
\text { Torrecilla Aznar, } \\
\text { 1999: } 409 . \\
\text { Lancaster, 2015: } \\
\text { fig. } 66\end{array}$ \\
\hline 10 & $\begin{array}{l}\text { Villa de Casas de } \\
\text { Luján, (Saelices, } \\
\text { Cuenca) }\end{array}$ & Termas & - & $\begin{array}{l}\text { Se documentan pivotes, } \\
\text { parecidos a los de las } \\
\text { dolia pero con un agujero } \\
\text { en el centro que ellos } \\
\text { interpretan como tubi } \\
\text { comparándolos con los de } \\
\text { Cabrera de Mar }\end{array}$ & S. I d.C. & $\begin{array}{l}\text { Urbina Martínez } \\
\text { y Morín de Pablo, } \\
2013 . \\
\text { Urbina Martínez et } \\
\text { al., 2013. } \\
\text { Morín de Pablo, } \\
\text { 2014: 393-413 }\end{array}$ \\
\hline 11 & $\begin{array}{l}\text { Cercadilla } \\
\text { (Córdoba) }\end{array}$ & $\begin{array}{l}\text { Termas del } \\
\text { conjunto palatino } \\
\text { Hab. C }\end{array}$ & $\begin{array}{l}\text { Bóveda } \\
3,06 \times 2,5 \mathrm{~m}\end{array}$ & $\begin{array}{l}15 \mathrm{~cm} \text { de longitud y } 6,5 \mathrm{~cm} \\
\text { diámetro }\end{array}$ & $\begin{array}{l}\text { Finales s. } \\
\text { III d.C. }- \\
\text { inicios s. IV } \\
\text { d.C. }\end{array}$ & $\begin{array}{l}\text { Hidalgo Prieto, } \\
\text { 1996: fig. } 54 . \\
\text { Torrecilla Aznar, } \\
\text { 1999: } 409 . \\
\text { Lancaster, } 2015: \\
\text { 101, fig. } 66 .\end{array}$ \\
\hline 12 & Tarragona & Necrópolis & - & - & $\begin{array}{l}\text { Sin } \\
\text { contexto }\end{array}$ & $\begin{array}{l}\text { Serra Vilarò 1929, } \\
\text { Lám. XXXVIII, nº } \\
1-3 . \\
\text { Storz, 1994: } 88 . \\
\text { Lancaster, 2015: } \\
\text { 101, fig. 66, nº } 7 .\end{array}$ \\
\hline 13 & Sagunto & $\begin{array}{l}\text { Museo } \\
\text { Arqueológico de } \\
\text { Sagunto }\end{array}$ & - & - & - & $\begin{array}{l}\text { Storz, 1994: } 88 \text { nota } \\
96 . \\
\text { Lancaster, } 2015 \text { : } \\
101 \text {, fig. } 66, \mathrm{n}^{\circ} 6 .\end{array}$ \\
\hline 14 & Mérida & $\begin{array}{l}\text { Museo Nacional } \\
\text { de Arte Romano }\end{array}$ & - & $\begin{array}{l}19 \text { tubos de distintas } \\
\text { procedencias, } 7 \text { de ellos de } \\
\text { libaciones }\end{array}$ & - & $\begin{array}{l}\text { Storz, 1994: 88, } \\
\text { nota } 95 .\end{array}$ \\
\hline
\end{tabular}

función de clave de la bóveda y otros dos tipos que actuarían como dovelas, con forma de vaso cerámico con un pequeño agujero en su base, con la peculiaridad de que uno de ellos presentaba un orificio o pasador central del cuerpo por donde se insertaría una varilla de hierro (Martín 2000: 160, fig. 4) (fig. 2). Los tubos tienen un diámetro de $11 \mathrm{~cm}$, con una longitud comprendida entre los 20-22 cm y tendrían su extremo apuntado, lo que ha llevado a Lancaster a denominarlos como bullet-shaped tubes (tubos con forma de bala) (Lancaster 2015: 102-105).
El referente tipológico previo más cercano lo encontramos en el balaneion norte de Morgantina (Sicilia), donde se documentó el uso más antiguo de construcción de bóvedas de cañón (habitaciones 8 y 9) y cúpula (habitación 5) usando tubos cerámicos ex profeso, con una cronología de mediados del siglo III a.C. (Lucore 2009: 43-59, 2013: 52-55). Lucore identifica dos tipos diferentes, realizados ambos a mano: el Tipo 1, parecido a una tubería de conducción de agua, sería una prueba de la adaptación de un modelo tecnológico preexistente a la edilicia; el Tipo 2 (0,60-0,70 m de largo; 0,12-0,15 m 
Figura 2. Tubi fittili provenientes de las termas republicanas de Cabrera de Mar.

Superior: reconstrucción de la cubierta a partir de la imagen publicada en Cabrera de Mar: arqueologia i patrimonio.

Fig. 18/23 http://www. cabrerademarpatrimoni. cat/rt_01.html. Inferior:

fotografías de los tubi fittili a partir del blog de Tocho T8 publicado el 9 de marzo de $2015 \mathrm{http}: / /$ tochoocho.blogspot. co.uk/2015/03/sistemaconstructivo-unicoromano.html.

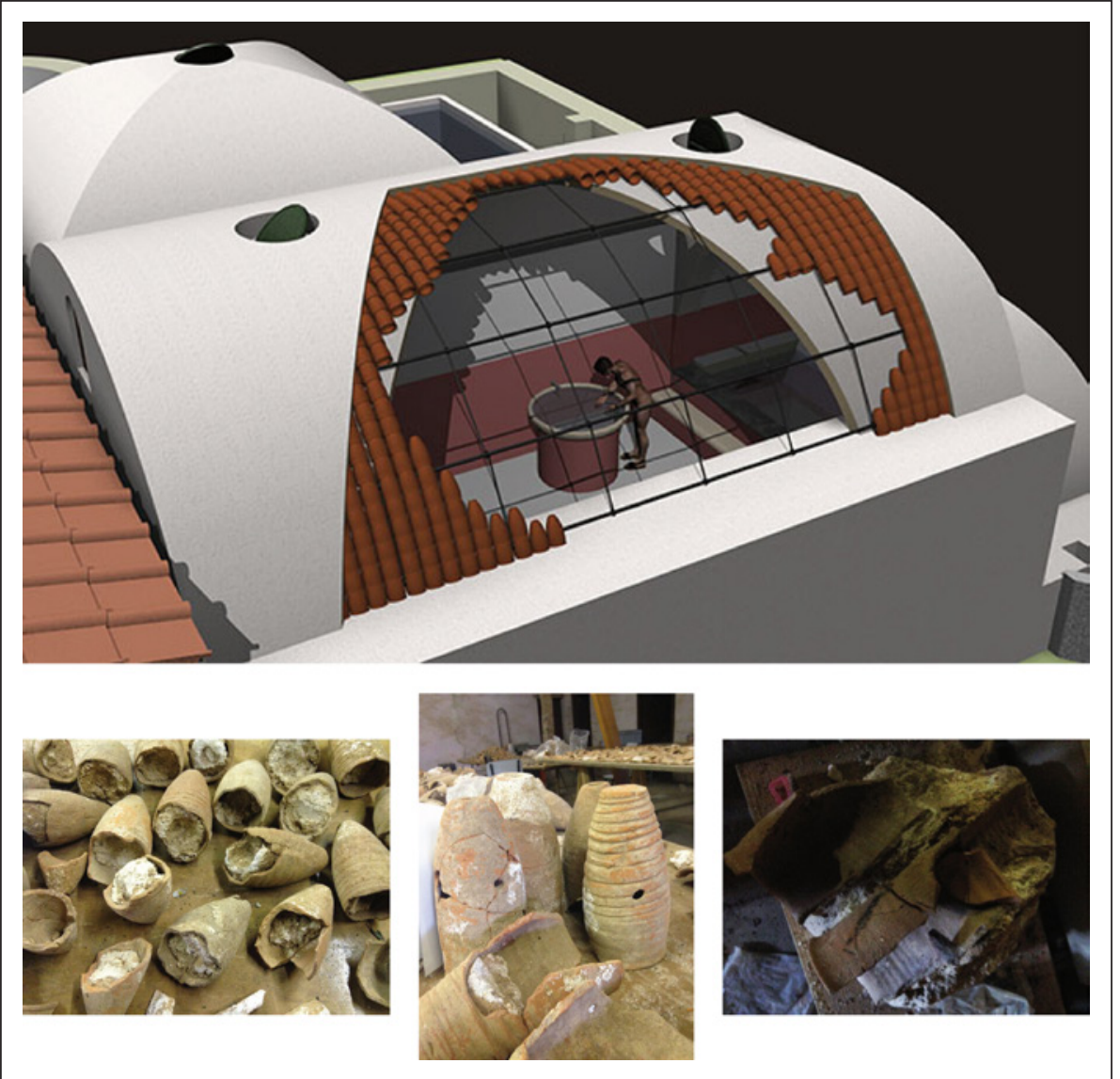

de diámetro interior) supondría una evolución del Tipo 1 a fin de hacerlo más apto para la construcción, más ligero, documentándose exclusivamente en la cúpula de la habitación 5 y en la bóveda de cañón de la sala 8 , mientras la sala 9 combina ambos tipos, pero prevaleciendo el Tipo 2. Al igual que sucede en las termas de Cabrera de Mar, utilizaron pasadores de hierro para dar una mayor estabilidad a las zonas más débiles de la cubierta y fueron finalmente recubiertos de mortero (Lucore 2009: 48-49).

\subsubsection{Casa de Hippolytus (Complutum, Alcalá de Henares, Madrid)}

La Casa de Hippolytus es un yacimiento arqueológico situado en la periferia de la ciudad romana de Complutum (Alcalá de Henares, Madrid), excavado de forma sistemática entre los años 1990 y 1998, bajo la dirección de Sebastián Rascón Marqués (2000: 203-218).

Pese a su denominación como casa, no nos encontramos ante un enclave doméstico suburbano, sino ante un complejo estructural mucho más extenso y complejo, cuya funcionalidad ha sido ampliamente debatida, presentándose dos interpretaciones distintas. Por un lado, que se trate de la sede de una schola, probablemente de un collegium iuvenum (Rascón y Polo 1996: 61-77; Rascón 2007: 119-152; 2016: 395-401); por otro lado, García Entero propone una interpretación funcional como complejo termal suburbano (García 2004: 143-158).

De las cuatro fases de construcción reconocidas, será durante la tercera de ellas -datada entre finales del siglo III d.C. hasta la segunda mitad del siglo IV d.C.- cuando se construya la estancia donde se ha documentado el uso de tubos cerámicos (Rascón 2007: 125-127).

$\mathrm{Al}$ norte del patio central cubierto/frigidarium se construyó una estancia de forma rectangular $(3,50$ $\mathrm{m}$ por 7,00 m), con dos accesos en sus lados largos (este y oeste), pavimentada en opus signinum y con un alzado del zócalo de los muros realizado en opus caementicium, cuyas esquinas fueron reforzadas con 
sillares (Rascón 2007: 130-131). Durante el proceso de excavación se pudo comprobar la existencia de un masivo derrumbe compuesto por tubos cerámicos que, en muchos casos, aún aparecían ensamblados, alterados solo por la presencia de dos sepulturas pertenecientes a la fase posterior (Rascón 2007: figs. 13) (fig. 3).

Los tubos cerámicos, con unas dimensiones que oscilan entre los 26 y los 18,6 cm de altura, un diámetro máximo entre 10,6 y 7,6 cm y un grosor de las paredes entre 7,2 y 0,6 cm (Durán 1998: 208), presentan una tipología variada, diferenciando, al menos, tres tipos, caracterizados por su forma de botella abierta, en este caso por ambos extremos, lo cual permitiría encajar unos tubos en otros. Además, se aprecian unas estrías producidas por su fabricación a torno, que podrían usarse para conseguir una mayor adherencia del mortero que se utilizaba para unirlos. La aparición de diferentes modelos estaría en relación con su posición en la bóveda (Rascón 1998: 208), arrancando directamente desde la propia corona del zócalo (Rascón 2007: figs. 14). Su tipología coincidiría con aquella que Lancaster denomina vaulting tubes with nozzles (Lancaster 2015: 106-108), característica del norte de África.

\subsubsection{La villa romana de Rabaçal (Penela, Coimbra)}

En el año 1984 se iniciaron las excavaciones en la villa romana de Rabaçal, ubicada en un lugar estratégico en la vía romana que unía Olisipo (Lisboa) y Bracara Augusta (Braga), a pocos kilómetros de Conimbriga. La cronología de ocupación de esta villa se inicia en la primera mitad del s. IV d.C., extendiéndose hasta el siglo V d.C. Los trabajos llevados a cabo han permitido conocer la pars urbana, organizada en torno a un peristilo de forma octogonal, la pars rustica y unos baños (Pessoa 1998).

Los tubos cerámicos fueron localizados, en su mayoría, en la sala de planta de cruz griega con ábsides en sus extremos, mientras un menor número de ellos provienen del área del balneario. Se han documentado cuatro tipos de tubos, los de mayor tamaño tienen una altura de $17,5 \mathrm{~cm}$, mientras los más pequeños tienen unas medidas de $15,5 \mathrm{~cm}, 13,5 \mathrm{~cm}$ y $9 \mathrm{~cm}$, con un diámetro de 6,5 cm (Pessoa 2004: 116) (fig. 4).

\subsubsection{Villa romana de los Vergeles (Granada)}

La villa romana de los Vergeles fue descubierta en la zona sur de la ciudad de Granada, concretamente, en el barrio homónimo (actuales calle Primavera y placeta Iliberis). Es, por tanto, una de las múltiples villas que poblaron el ager de la antigua Florentia Iliberritana. Su hallazgo se produjo en 1989, dejando al descubierto parte del balneum de una villa (Pérez y Toro 1991: 228-232). La posterior aparición de un pavimento musivo propició la realización de una nueva intervención de urgencia, que sacó a la luz nuevas estancias de la pars urbana (Fresneda et al. 1993: 149-156).

Según sus excavadores, las primeras evidencias de ocupación datan del siglo I d.C., con una remodelación en los siglos II-III d.C., cuando se produce una ampliación del balneum. En el siglo IV d.C. se construyen dos salas rectangulares terminadas en ábside, pavimentadas en opus tessellatum, que serán amortizadas completamente a finales del siglo $\mathrm{V}$ d.C. con la instalación de una necrópolis (Marín 2011: 176).

Las salas con ábside han sido identificadas con un triclinium y un oecus, es decir, con estancias de representación de la pars urbana de este complejo rural. El primero de estos ámbitos tiene unas dimensiones de $11,5 \mathrm{~m}$ de longitud por 4,90 $\mathrm{m}$ de anchura, y el segundo, $12,7 \mathrm{~m}$ por 4,00 m, estando ambos decorados con mosaicos (Marín 2016: 148-166). En los niveles de derumbe se documentaron un gran número de tegulae, así como ladrillos y piedras, que cubrían otro estrato formado por tubos cerámicos unidos entre sí.

En este caso, los tubos cerámicos tienen unas dimensiones de $22 \mathrm{~cm}$ de longitud por $6 \mathrm{~cm}$ de diámetro, que en ocasiones, incluso, aparecían unidos formando conjuntos de hasta tres hiladas paralelas (Fresneda et al. 1993: 151, foto 3) (fig. 5). La descripción de este derrumbe, junto a la documentación fotográfica, permite proponer el cubrimiento de estas estancias abovedadas con un complejo sistema de techumbre, formado por tubos cerámicos en el interior y por tégulas al exterior. Desgraciadamente, las imprecisas descripciones impiden saber si pudieron estar cubriendo las dos salas, solo una de ellas o, incluso, únicamente la parte absidada de una o ambas estancias.

\subsubsection{Villa romana de Salar (Salar, Granada)}

La villa romana de Salar (Granada) se enmarca en la región del Poniente granadino, en la comarca histórica de Loja. El descubrimiento de esta villa romana se produjo en el año 2004, con motivo de la instalación de una estación depuradora de aguas residuales. Desde entonces se desarrollaron varias campañas de excavación, divididas en diferentes fases, entre los años 2006 y 2013, y 
Figura 3. Tubi fittili de la Casa de Hippolytus (Complutum). Superior: imagen de los tubos cerámicos en el momento de su excavación (Rascón 2007: 131, fig. 13). Inferior izquierda: fotografía de los tipos diferentes de tubi fittili (Durán 1998: 208). Inferior derecha: reconstrucción de la bóveda (Rascón 2007: 131, fig. 14).

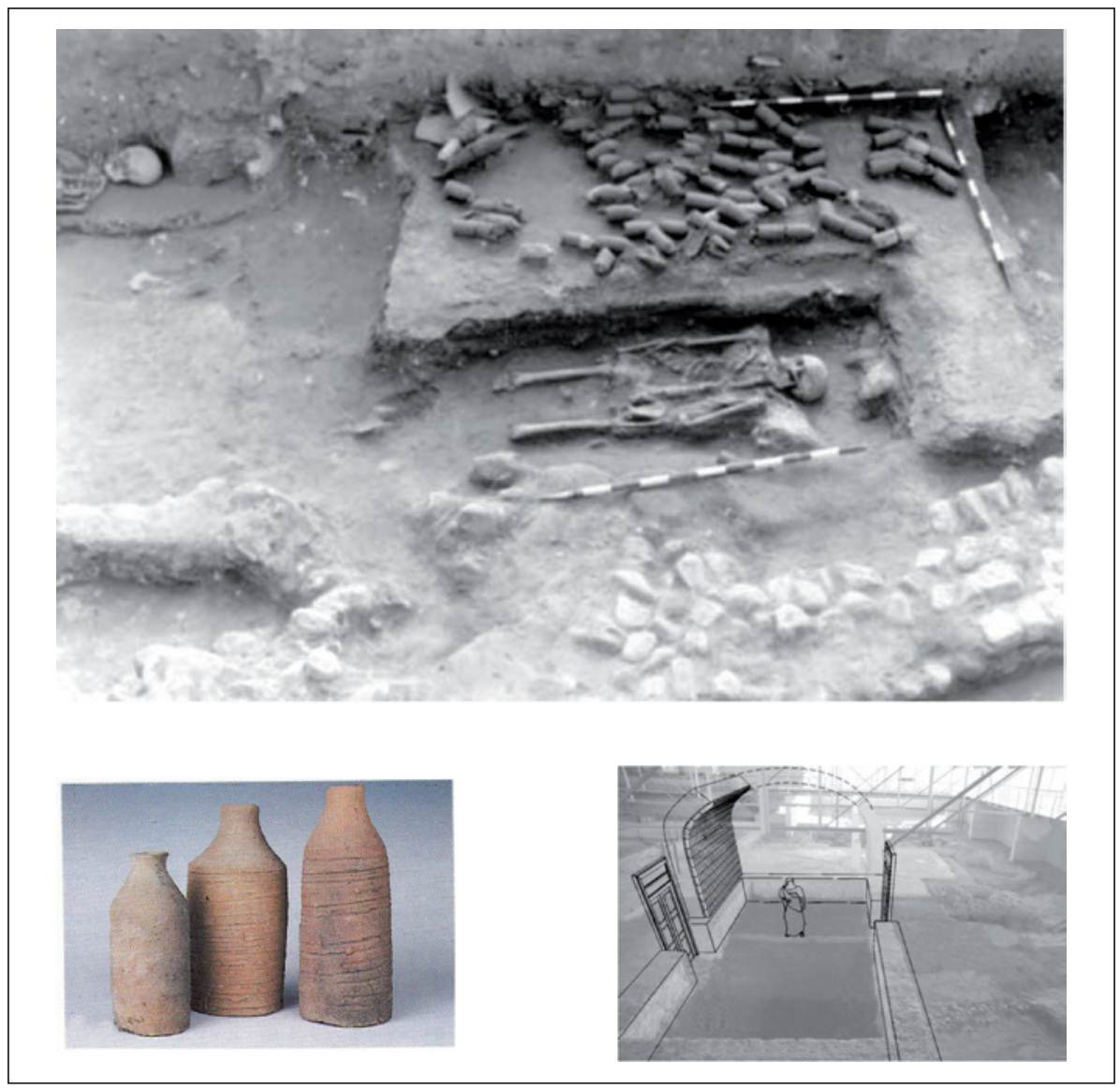

en las cuales se documentaron restos de una lujosa villa romana (El-Amrani 2013; González 2014a, 2014b). En el año 2016, el Ayuntamiento de Salar decidió encargar la investigación de este importante yacimiento arqueológico a un grupo de profesionales de la Universidad de Granada (entre los que se encuentran los aquí firmantes), con el objeto de plantear un proyecto de investigación a medio plazo que consiguiera explorar todas las potencialidades que encierra esta villa romana.

Las intervenciones arqueológicas llevadas a cabo de manera discontinua entre 2006 y 2013, por anteriores equipos de trabajo, dejaron al descubierto varias estancias que conforman la pars urbana de esta villa (fig. 6). En concreto, se trata de parte del peristylum, presidido por un gran triclinium que cuenta con un ninfeo en la cabecera, conectado a un estanque con forma de "U" que rodea buena parte del triclinium. El conjunto se completa con habitaciones a sendos lados de los pasillos del peristylum, siendo el Complejo Estructural CE-03 la mejor conocida, hasta el momento. En cuanto a la cronología de esta villa, con origen en las

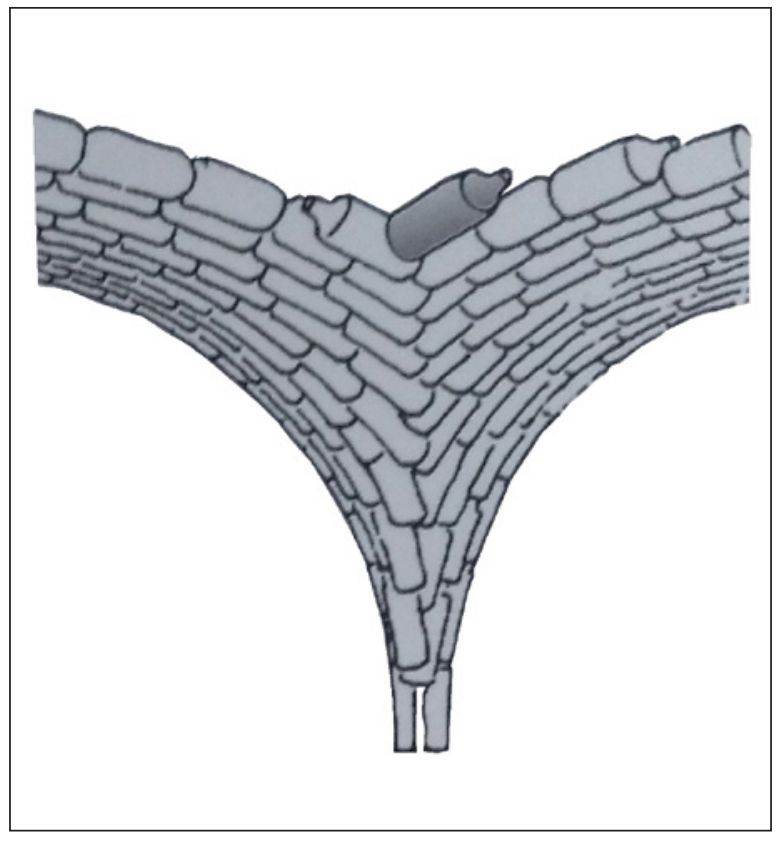

Figura. 4. Reconstrucción hipotética de la cubierta con tubi fittili de la villa romana de Rabaçal (Pessoa 2004: 116). 
primeras décadas del s. I d.C., se ha observado una fase de monumentalización a partir del siglo III d.C., como apunta el estudio de los materiales, así como una fase de reparación de sus mosaicos que puede datarse en el siglo V d.C. Finalmente, podemos fijar la fecha del final de la villa a partir de un nivel generalizado de incendio, que se produciría en la primera mitad del siglo VI d.C.

Uno de los objetivos principales de la nueva intervención arqueológica, iniciada en el verano de 2016 y ya con el actual equipo de investigación que firma este trabajo, era documentar una sala parcialmente excavada, el complejo estructural CE-03. Esta estancia, en la esquina sureste del peristilo, se distribuye en torno a un espacio central al que se abren dos espacios o cubículos rectangulares hacia el noreste y sureste. La técnica edilicia empleada para la construcción de los muros es el opus mixtum, combinando materiales pétreos con latericios, mientras el pavimento es un suelo de tierra apisonada, de color amarillento, muy firme y con presencia de cal. El sistema de cubierta abovedado de esta estancia se deduce de la presencia masiva de tubos cerámicos documentados en el registro arqueológico. El diseño original de cierre resultaría de un sistema mixto para la zona central, que combina nervaduras de tubos cerámicos al interior -revestidos con un estucado blanco de cal-y cubiertos, a su vez, por tegulae, al exterior. Destaca la abundante presencia de opus signinum, que documentamos unido en la parte superior y, por tanto, exterior de los tubos, y entre estos y las tegulae, por lo que hemos asociado su utilización a la construcción de la cubierta. Por otro lado, los cubículos tendrían una cubierta más simple, utilizando un sistema tradicional de armazón de madera y tegulae (Moreno et al. e.p.) (fig. 7).

Respecto a los tubos cerámicos provenientes del CE-03, fueron realizados ex profeso a torno, con unos diámetros que oscilan entre los 7 y $7,5 \mathrm{~cm}$, mientras su altura suele ser homogénea, en torno a $16 \mathrm{~cm}$. De este modo, se configura un módulo de 16 x 7/7,5 cm y con la forma de botella truncada en su base y apuntada en la parte superior, por lo que pertenecería al tipo que Lancaster denomina terracotta vaulting tubes with nozzle. En cuanto al estudio macroscópico de sus pastas, se han observado dos tipos distintos de pastas de cocciones oxidantes, o bien marrón clara/beige oscura o bien amarillenta, bien depuradas, con numerosas inclusiones muy finas de mica blanca y dorada en las pastas marrones y beiges, siendo muy escasas en las pastas amarillentas, y, al contrario, frecuentes inclusiones de pequeño tamaño calcáreas, marrones, negras y grisáceas en las pastas marrones/beiges, que son más numerosas y mayoritarias respecto a las micáceas en las pastas amarillentas. Por otro lado, sabemos de la existencia de tubos cerámicos para bóvedas en la zona del ninfeo, pero desconocemos los detalles de su hallazgo, ya que sus excavadores aún no han publicado el trabajo correspondiente. No obstante, hemos localizado, entre el material arqueológico depositado temporalmente en las dependencias del Ayuntamiento de Salar, varias cajas con $t u b i$, con la etiqueta "Ninfeo". Esto, junto a una breve referencia a su hallazgo en dicho espacio, en una memoria de excavación (El Amrany 2015) nos permitió su posterior análisis.

Aunque hemos apreciado tubos que siguen el módulo de los documentados en el CE-03 y realizados con las mismas pastas, la mayoría de ellos son más pequeños, con módulos que oscilan entre los 16 x 6,5 cm y los 14,5 × $6 \mathrm{~cm}$. Como ya hemos indicado, la falta de documentación gráfica, fotográfica o de cualquier otro tipo, referente a su exacta posición nos impide establecer conclusión alguna referente a su utilización, si bien parece evidente que debieron combinarse en lugares distintos de la semicubierta abovedada del ninfeo, atendiendo a una función específica (fig. 8).

En el momento actual de la investigación, desconocemos la funcionalidad original que debió adquirir esta estancia. A partir del estudio de los materiales exhumados, estuvo en uso hasta la primera mitad del siglo VI d.C., como espacio doméstico en el momento de su destrucción.

\subsection{Tubi fittili de difícil adscripción para la construcción de bóvedas, conocidos a partir de sus descripciones}

\subsubsection{Villa romana de Els Munts (Altafulla)}

Un nuevo testimonio de utilización de tubos cerámicos en la construcción de bóvedas se encontraría en los baños de la villa romana de Els Munts (Altafulla, Tarragona), a menos de $100 \mathrm{~km}$ al sur de las termas republicanas de Cabrera de Mar. Sin embargo, pese a su proximidad geográfica, el contexto histórico de su desarrollo es muy diverso.

Las termas inferiores son una de las zonas excavadas en mayor extensión dentro de las estructuras de la villa; sin embargo, eso no garantiza un óptimo conocimiento de su estratigrafía, materiales y contextos, ya que los trabajos arqueológicos fueron iniciados en el año 1970, de la mano de P. M. Berges Soriano (Otiña 2005: 220-227), con la metodología propia del 


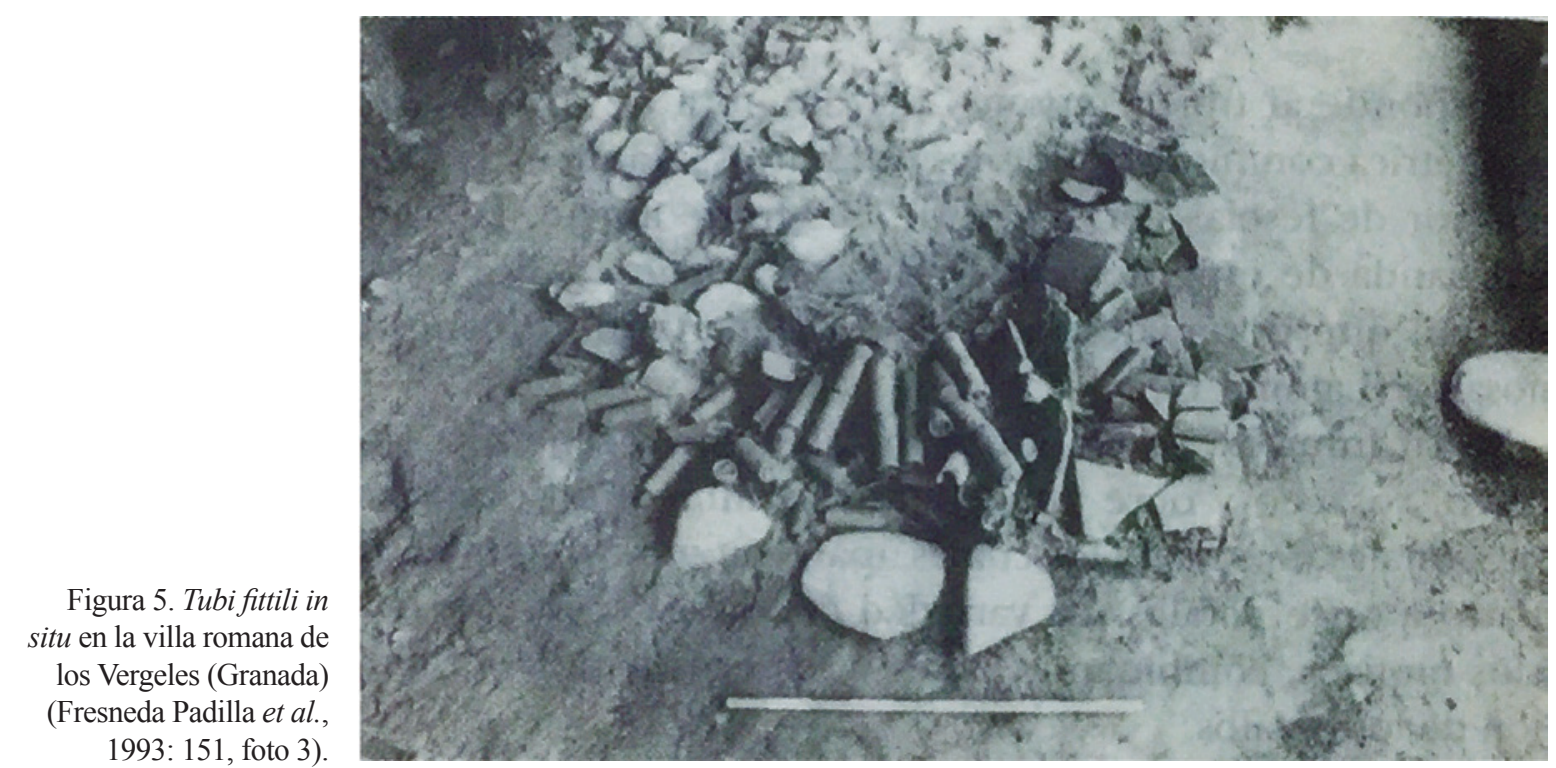

momento. El hallazgo de los tubos cerámicos se produciría en el frigidarium, identificado con el número 3 en la planimetría de Berges (1977: 38, fig. 3).

Respecto a la construcción del frigidarium $(6,20 \mathrm{~m}$ por 5,70 m), el propio excavador expresó: «a juzgar por los materiales del estrato de destrucción y abandono de las termas, estuvieron cubiertas por bóvedas de tubos, según se desprende de la gran cantidad de ellos recuperados», con una cronología que él sitúa en la segunda mitad del siglo III d.C., y con la funcionalidad de aligerar el peso de la bóveda (Berges 1977: 42). Esta es la única información existente respecto al uso de tubos cerámicos para la bóveda del frigidarium, no existiendo ningún tipo de descripción, dibujo o número de tubos exhumados. Con el interés de conocer si se registraron o guardaron algunos de estos tubos, nos hemos puesto en contacto con el Museu Nacional Arqueòlogic de Tarragona. Desde su servicio de investigaciones nos alertan de la precariedad e insuficiente documentación de los materiales procedentes de estas excavaciones, de los que no existen fotografías, planimetrías o inventarios, por lo que se hace muy complicado rastrear el uso de estos tubos cerámicos que, de ser recogidos, se encontrarían en los fondos antiguos del Museo.

Ante la debilidad de las evidencias aportadas, investigadores posteriores han puesto en duda la construcción de esta bóveda con tubos cerámicos y proponen una cubierta de madera (López 1993: 64). A su vez, se establecen dos fases para la construcción de las termas, con una violenta destrucción intermedia debido a un incendio, en torno al 260 d.C., que afectaría a la totalidad de las estructuras de la villa. Para la primera fase se rebaja la cronología a mediados del siglo II d.C., que Berges situaba en el s. III d.C. -a ella correspondería la posible cubierta con tubos cerámicos del frigidarium-. En la segunda fase, fechada en la segunda mitad del siglo IV d.C., se produciría una importante remodelación del frigidarium, ampliando y cambiando la forma de sus piscinas; sin embargo, no se especifica cómo sería la cubierta de este segundo período (López 1993: 63-67).

Desconocemos el número de tubos que se documentaron, sus dimensiones y tipología, pudiendo estos pertenecer al sistema de calefacción (concameratio) o a otra tipología de bóvedas que, utilizando tubos cerámicos en su construcción, no se asocian con el modelo de edilicia aquí analizado. Además, en cuanto a su cronología, se vincula con la construcción de la primera fase del frigidarium, sin justificar su aparición sobre los mosaicos asociados a la segunda fase. La parquedad de los datos nos lleva a poner en duda la construcción de una bóveda con tubos cerámicos en el frigidarium de los baños de la villa de Els Munts.

\subsubsection{Villa romana de Las Gabias (Gabia la Grande, Granada)}

A inicios de la década de los años 20 del pasado siglo, se llevaron a cabo varias intervenciones arqueológicas en la conocida como villa romana de Gabia la Grande. El conjunto arqueológico documentado se compone de una villa, fechada desde el siglo I al IV 


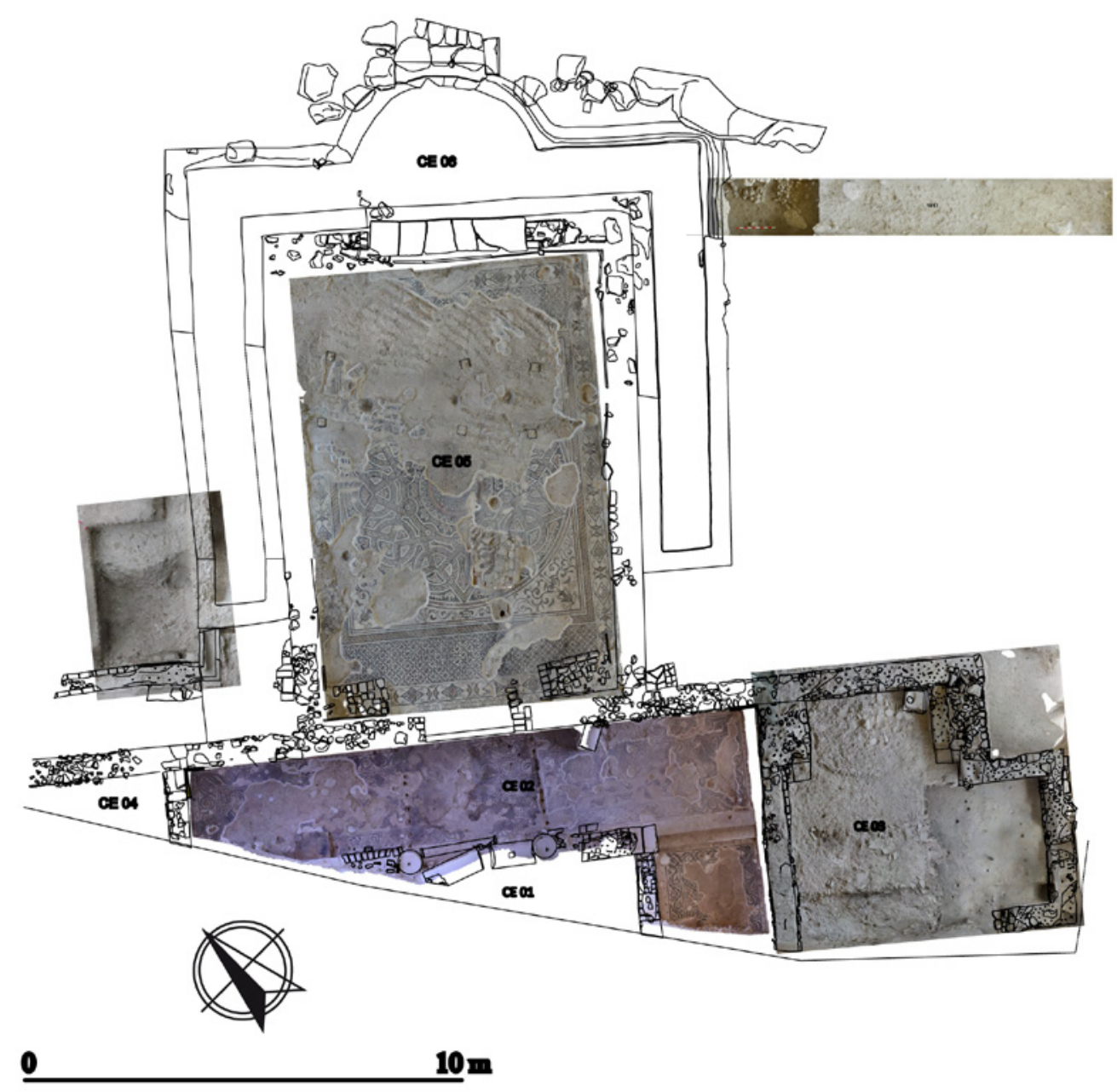

Figura 6. Planimetría de la villa romana de Salar con los sectores excavados en el año 2016 (elaboración propia a partir de imagen tomada de la "Memoria de intervención para la conservación de la villa romana del Salar (Granada)", elaborada por Siglos. Conservación y restauración, S.L.).

d.C., y un edificio denominado Monumento Subterráneo o Criptopórtico, sobre el cual se han propuesto diferentes interpretaciones, sin que ninguna se haya dado por concluyente (Pareja y Sotomayor 1979: 423-440).

Cabré señalaba lo siguiente con respecto a unas estancias próximas al criptopórtico:

"No debo dar por terminada esta segunda parte de mi informe sin antes exponer un dato de gran interés, por el que se vislumbra de una manera bien clara la civilización a que pertenecen las ruinas de Gabia la Grande; dato que aportaron mis excavaciones, pero al que no di importancia cuando redacté estas líneas y que luego, al exponerlo verbalmente a mi maestro don Manuel Gómez Moreno, me llamó la atención sobre el mismo y me hizo ver su gran importancia arqueológica. Se trata de unos tubos de barro cocido, con terminación cónica, que se enchufan unos con otros, con una mezcla de cal y arena; los cuales encontré en bastante cantidad en la cámara que se citará después, que tiene un banco corrido adosado a un 


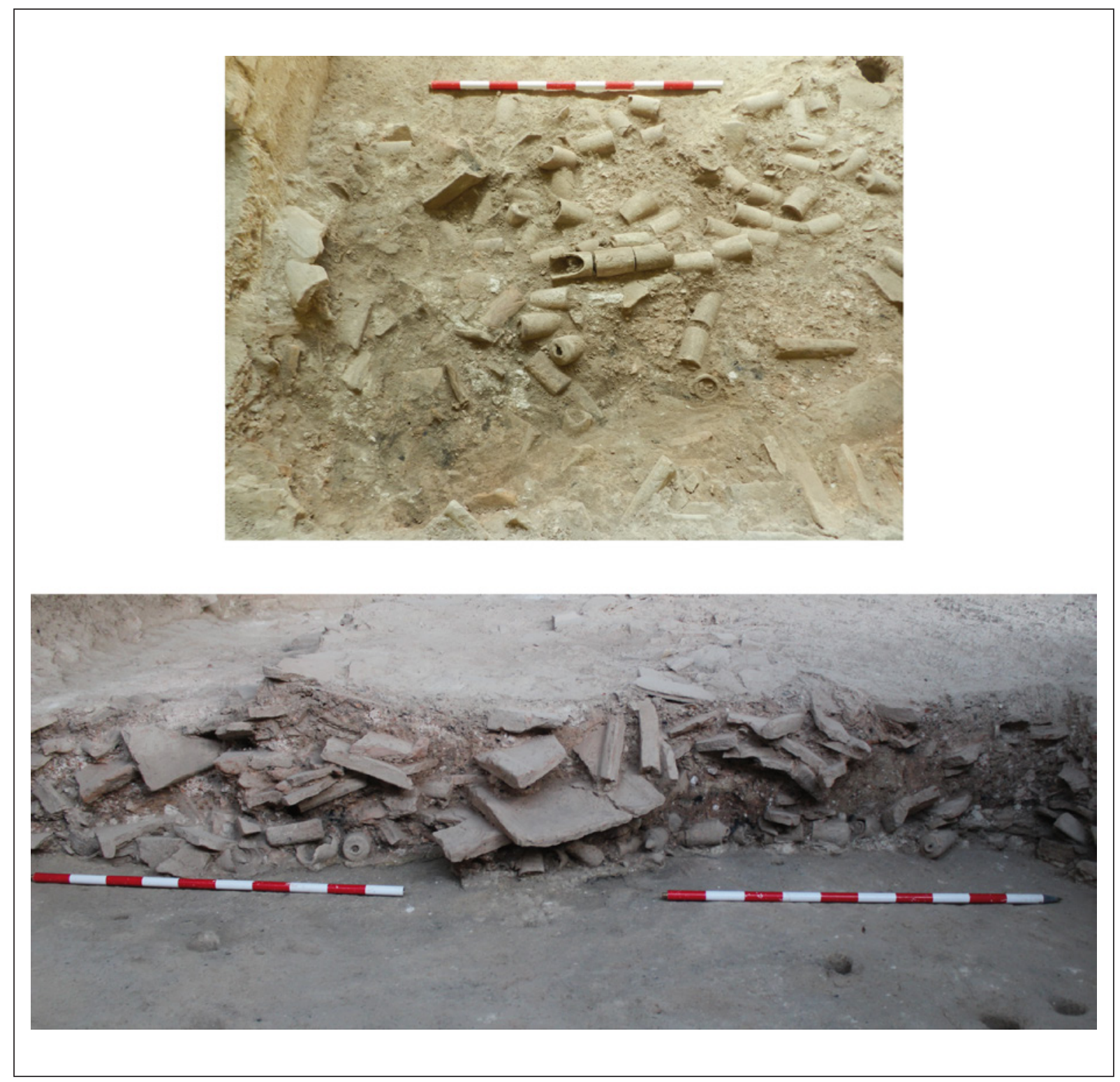

Figura 7. Tubi fittili in situ en el CE-03 en la villa romana de Salar (Granada).

muro de ella. Estos tubos miden unos 15 centímetros de longitud y son todos iguales" (Cabré 1923: 11).

De esta descripción parece evidente el carácter de tubos para la conformación de cubiertas abovedadas; hecho que se podría confirmar si atendemos a que en el Museo Arqueológico y Etnológico de Granada existe una vitrina donde, entre otras piezas procedentes de esta excavación, se exponen tres de aquellos tubi engarzados.

Por tanto, podemos sumar a la exigua lista de lugares hispanos donde se ha documentado el uso de tubos cerámicos para la realización de cubiertas curvas, el caso de la villa romana de Las Gabias.

\subsubsection{Villa romana de Daragoleja \\ (Pinos Puente, Granada)}

La villa de Daragoleja fue descubierta en la segunda mitad del siglo XIX, en las proximidades de Pinos Puente (Granada). En la actualidad, desconocemos el lugar exacto donde se encuentra ya que volvió a ser 
sepultada y tan solo conservamos el informe decimonónico realizado (Oliver y Gómez 1870), así como algunos restos de cultura material que fueron donados al Museo Arqueológico de Granada. Esta villa destacaba por la importancia de sus mosaicos y la cronología tardía de su ocupación, que situaron en los siglos IV-V d.C.

Al tratarse de una excavación tan antigua no existen registros de materiales, tan solo aquellos que fueron donados al museo. Entre ellos, aparte de fragmentos cerámicos y materiales de construcción, se depositaron cuatro tubos cerámicos (Marín 2016: 263). Estos tubos, que podrían estar relacionados con la construcción de una sala abovedada, deben ser, sin embargo, desestimados por la falta de evidencias suficientes, ya que desconocemos por completo el contexto de su aparición, que incluso podría estar relacionado con una figlina (Marín 2016: 264). Además, en relación con la problemática sobre su denominación y diferenciación con los tubos para la conducción de agua, sabemos que la villa disponía de estos últimos (Fernández 1978: 327), por lo que no es posible afirmar la construcción de una bóveda con tubos cerámicos.

\subsection{Tubi fittili descartados para la construcción de bóvedas}

\subsubsection{Vilar de Santos (Orense)}

Según López Cuevillas, al abrirse una zanja en las inmediaciones de la iglesia de esta parroquia, se descubrieron más de 50 vasijas de barro completas, de forma abarrilada, colocadas de forma vertical, formando un círculo y, literalmente, «enchufadas unas en otras, dos a dos» (López 1953: 437). Sus dimensiones son de 22 $\mathrm{cm}$ de alto, con un diámetro en su boca de 9,50 cm y con líneas incisas a modo de decoración en su parte más ancha, atribuyéndoles, por tanto, una función de recipiente de almacenaje (López 1953: 437). A partir de esta descripción, Torrecilla Aznar (1999: 409) considera que pueden corresponder con la descripción de tubi fittili y así es recogido por Lancaster, tanto en su mapa de distribución de presencia de tubos cerámicos como en su base de datos (Lancaster 2015: fig. 66).

Sin embargo, y ante la parquedad de los datos aportados, creemos necesario descartar la presencia de tubos cerámicos para la construcción de bóvedas en Parada de Outeiro. En primer lugar, el tamaño de estas piezas $(22 \mathrm{~cm})$ haría que estuviesen relacionadas con las primeras producciones asociadas a Morgantina, con una cronología del siglo III a.C., mientras las evidencias arqueológicas documentadas en las proximidades de las vasijas datan de época tardorromana. En segundo lugar, no nos parece ilógico el planteamiento original de López Cuevillas de que se trate de piezas cerámicas de almacenaje, más cuando no disponemos de dibujos o fotografías que nos ayuden a su identificación. Además, la propia descripción del hallazgo evidencia que, sin entrar a valorar su función, no puede en ningún caso proceder del derrumbe de una bóveda, ya que es altamente improbable que, tal y como indican sus excavadores, apareciesen en el registro en posición vertical y unidos de dos en dos, ni tampoco adquiriendo el conjunto una forma circular perceptible.

\subsubsection{Villa romana de Casas de Luján (Cuenca)}

La villa romana de Casas de Luján se ubica en el territorium de la ciudad romana de Segóbriga, de la que dista $3,5 \mathrm{~km}$. El descubrimiento de este enclave rural se produjo en el año 2010, habiéndose identificado una almazara con varias piletas de decantación de aceite, un taller alfarero con dos hornos y los restos parciales de un balneum (Urbina y Morín 2013: 31-35; Urbina et al. 2013: 194; Morín 2014: 395). En cuanto a la cronología, se data la construcción de la villa en el primer cuarto del siglo I d.C., mientras su destrucción se produciría en el mismo momento en que algunas de sus salas se estaban remodelando, a finales del mismo siglo, de forma repentina.

Nuestro interés vuelve a radicar en los baños de esta villa, concretamente en la estancia donde se sitúa la $n a-$ tatio, interpretada como frigidarium (Urbina y Morín 2013: 69-80; Urbina et al. 2013: 194-199; Morín 2014: 402-407).

Entre los materiales documentados en el derrumbe que rellenaba la natatio, se recuperaron dos fragmentos de dolia de color ocre con un agujero en su base (Urbina y Morín 2013: 136). Según su descripción, serían vasos cerámicos parecidos a bases de dolia $(10 \mathrm{~cm}$ de diámetro), con un agujero en la parte central $(1,6 \mathrm{~cm}$ diámetro) realizado en el proceso de fabricación de la pieza. Sus excavadores proponen que estas piezas serían similares a los tubos cerámicos que ya hemos analizado en el ejemplo de las termas de Cabrera de Mar (Urbina y Morín 2013: 109-110; Urbina et al. 2013: 202-fig. 14A, 203; Morín 2014: 408).

Analizando la imagen publicada (Urbina et al. 2013: 202, fig. 14A) (fig. 9), y en comparación con aquellos de Cabrera de Mar, la medida de los tubos 


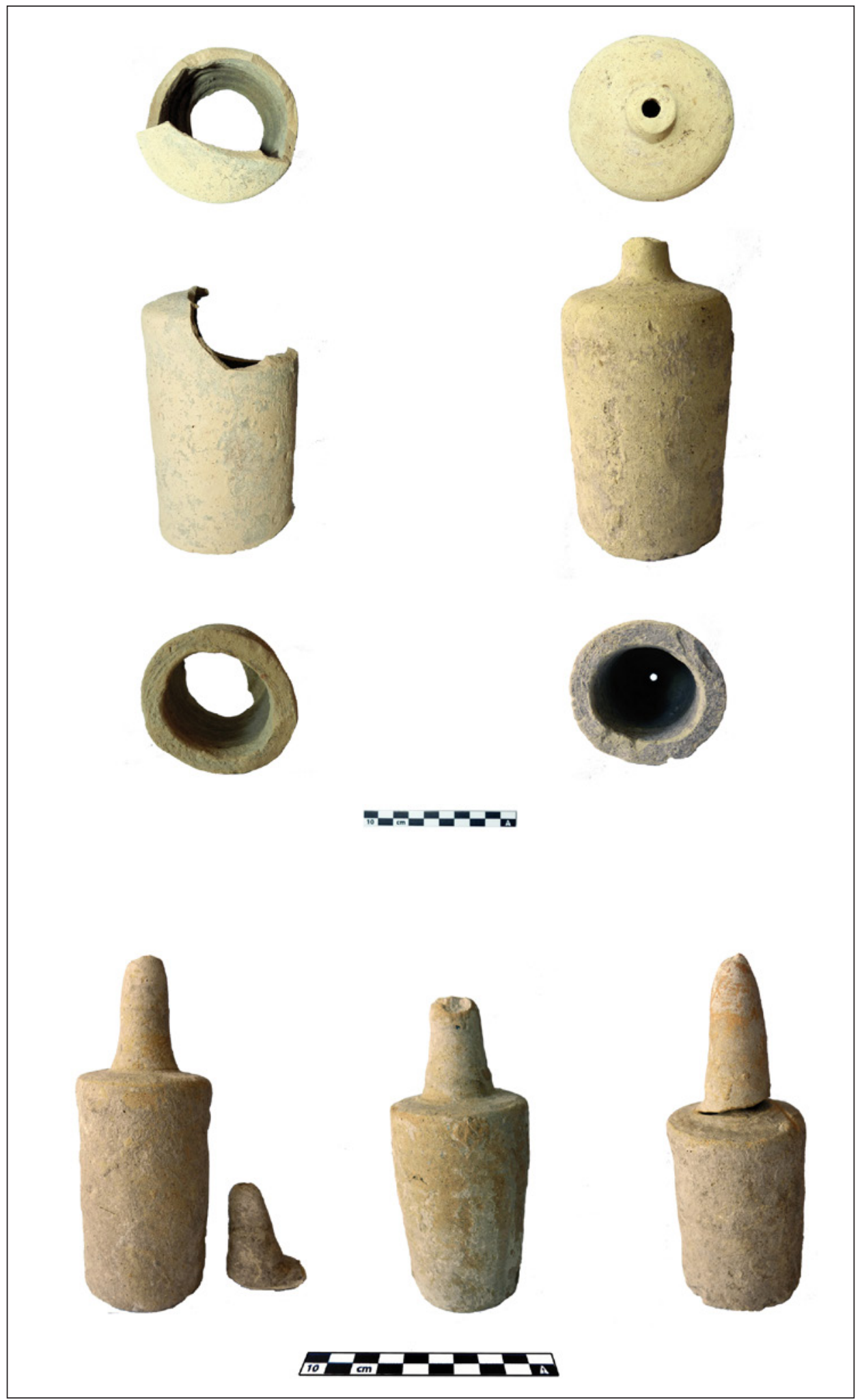

Fig. 8. Superior: tubi fittili del espacio CE-03 de la villa de Salar. Inferior: tubi fittili provenientes de la zona del ninfeo de la villa de Salar. 


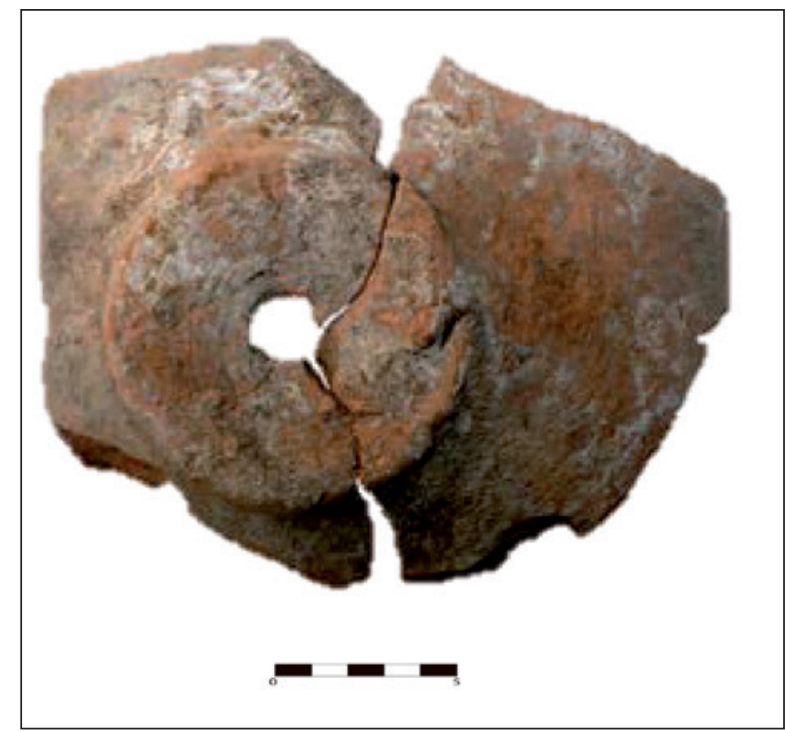

Figura 9. Piezas documentadas en la villa romana de Casas de Luján (Urbina et al. 2013: 202, fig. 14A).

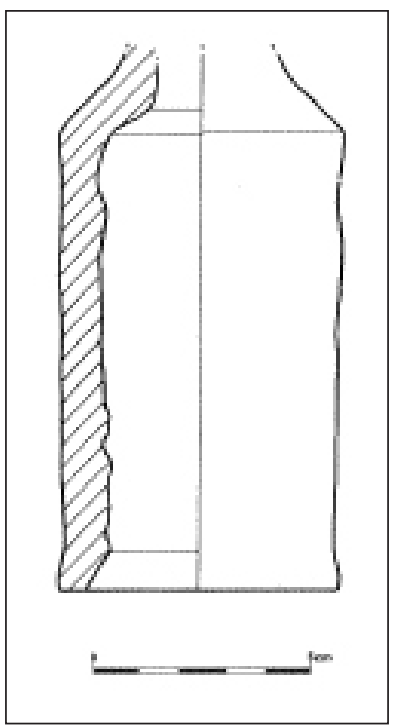

Figura 10. Dibujo de un tubo cerámico de Cercadilla (Córdoba) (Hidalgo 1996: fig. 54).

de Cabrera es de $11 \mathrm{~cm}$; sin embargo, en Casas de Luján solo la base ya mide $10 \mathrm{~cm}$ y, como se observa, su cuerpo sería mucho más ancho, con paredes exvasadas desde dicha base. Respecto al orificio en el fondo, tampoco coincidiría, ya que en Cabrera de Mar es un pequeño agujero menor de 1,6 cm (Martín 2000: 160). La cronología de ambos complejos es muy lejana, desde la segunda mitad del siglo II a.C. de Cabrera de Mar, hasta el siglo I d.C. cuando se edifica la villa de Casas de Luján. Por otro lado, y como ya hemos incidido, la aparición de dos tubos no puede asociarse con la construcción de una bóveda de esta tipología. Ante estos datos, consideramos que no se puede justificar la construcción de una bóveda de tubos cerámicos en el frigidarium de la villa romana de Casas de Luján.

\subsubsection{Cercadilla (Córdoba)}

El conjunto arqueológico de Cercadilla se encontraba en la periferia de la Colonia Patricia Corduba, construido a finales del siglo III d.C. o comienzos del siglo IV d.C. Nos encontramos ante un monumento de una gran envergadura, con $400 \mathrm{~m}$ de largo por $200 \mathrm{~m}$ de ancho, cuya funcionalidad e interpretación ha sido muy debatida: palatium imperial de Maximiano Hercúleo, construido entre los años 293-305 (Hidalgo 1996); episcopium de Osio, obispo de Córdoba (Marfil 2001: 117-142; Corzo 2009: 111-131; Marfil 2010-2011: 241-252); o villa bajoimperial de uso privado (Arce 2010: 397-412), argumentos que Hidalgo Prieto (2014: 217-241) pone en duda.

De los diferentes espacios que componen este conjunto termal, nos centraremos en los designados con las letras C, D y D' (sudatorium y caldarium, respectivamente), ya que en el nivel de saqueo de las suspensurae se documentaron fragmentos de los que Hidalgo Prieto denomina como tubuli. Se trata de tubos cerámicos de forma cilíndrica y de una longitud inferior a los $15 \mathrm{~cm}$, diseñados para encajar unos en otros (Hidalgo 1996: fig. 54) (fig. 10). Es de destacar que ninguno de ellos se localizó en su lugar de origen, pero se apunta a su posible utilización en el sistema de calefacción para las paredes y como método para la salida al exterior de los gases calientes provocados por los hornos (Hidalgo 1996: 86, 89-90 y 126-127).

Será Torrecilla (1999: 409), recogido posteriormente por Lancaster (2015: 101, fig. 66), quien identifique estas piezas con "tubi fictiles" y afirme que estas salas estaban cubiertas con bóvedas realizadas con tubos cerámicos que permitían el paso del aire caliente. Nuestro planteamiento está en contra de esta afirmación ya que no existe ningún tipo de dato que pueda corroborarlo. En primer lugar, la localización de estos tubos en un contexto de saqueo, en el que el propio investigador no puede determinar su lugar original de uso, invalida una afirmación tan categórica. Finalmente, no puede ser descartada la propuesta de que se trate de tubos abiertos por ambos extremos, adosados a las paredes, utilizados para la salida de los gases. 


\subsubsection{Tarraco}

Lancaster contempla la construcción de una bóveda con tubos cerámicos en Tarraco (Lancaster 2015: 101, fig. 66, $\mathrm{n}^{\mathrm{o}} 7$ ), recogiendo el testimonio anterior de Storz (1994: 88). La publicación original donde se encuentran los tubos es de 1928, proveniente de las excavaciones de Serra Vilarò en la necrópolis romano-cristiana de Tarragona (Serra 1929).

Se trata de tres tubos: dos de pequeño tamaño pertenecientes a la misma tipología, pudiéndose apreciar que el número 2 estaba abierto por ambos extremos, posiblemente igual que el número 1; y un tercero, más largo que los anteriores pero fragmentado en su extremo, lo que impide reconocer si estaba también abierto por ambas partes (Serra 1929, Lám. XXXVIII, $\mathrm{n}^{\mathrm{o}} 1-3$ ) (fig. 11).

Teniendo en cuenta el contexto arqueológico en el que fueron hallados, correspondiente a una necrópolis, así como el reducido número de tubos documentados, y que al menos uno de ellos está abierto por ambos extremos, debemos descartar completamente la construcción de una bóveda de tubos cerámicos en este lugar a partir de dichas evidencias y consideramos que nos encontramos ante tubos de libaciones, ampliamente documentados en otras necrópolis de época romana.

\subsubsection{Museo Arqueológico de Sagunto}

Respecto a la utilización de tubos cerámicos en la construcción de bóvedas en Sagunto, muy poco podemos aportar al respecto. La única mención que conocemos proviene de la obra de Storz, que localiza, con la ayuda de Mercedes Vegas (Storz 1994: 88, nota 96), la presencia de algunas de estas piezas en el Museo Arqueológico de dicha localidad. Por tanto, con la información de la que actualmente disponemos, no podemos considerar Sagunto como un punto a reseñar en nuestro mapa de distribución de esta técnica edilicia en Hispania.

\subsubsection{Museo Nacional de Arte Romano de Mérida}

La información acerca de la presencia de tubos cerámicos para bóvedas en el Museo de Mérida proviene de Storz (1994: 88, nota 95), quien obtiene la referencia a través de un informante, que refleja la problemática de la confusión entre los tubos cerámicos para bóvedas con aquellos para libaciones (fig. 12).

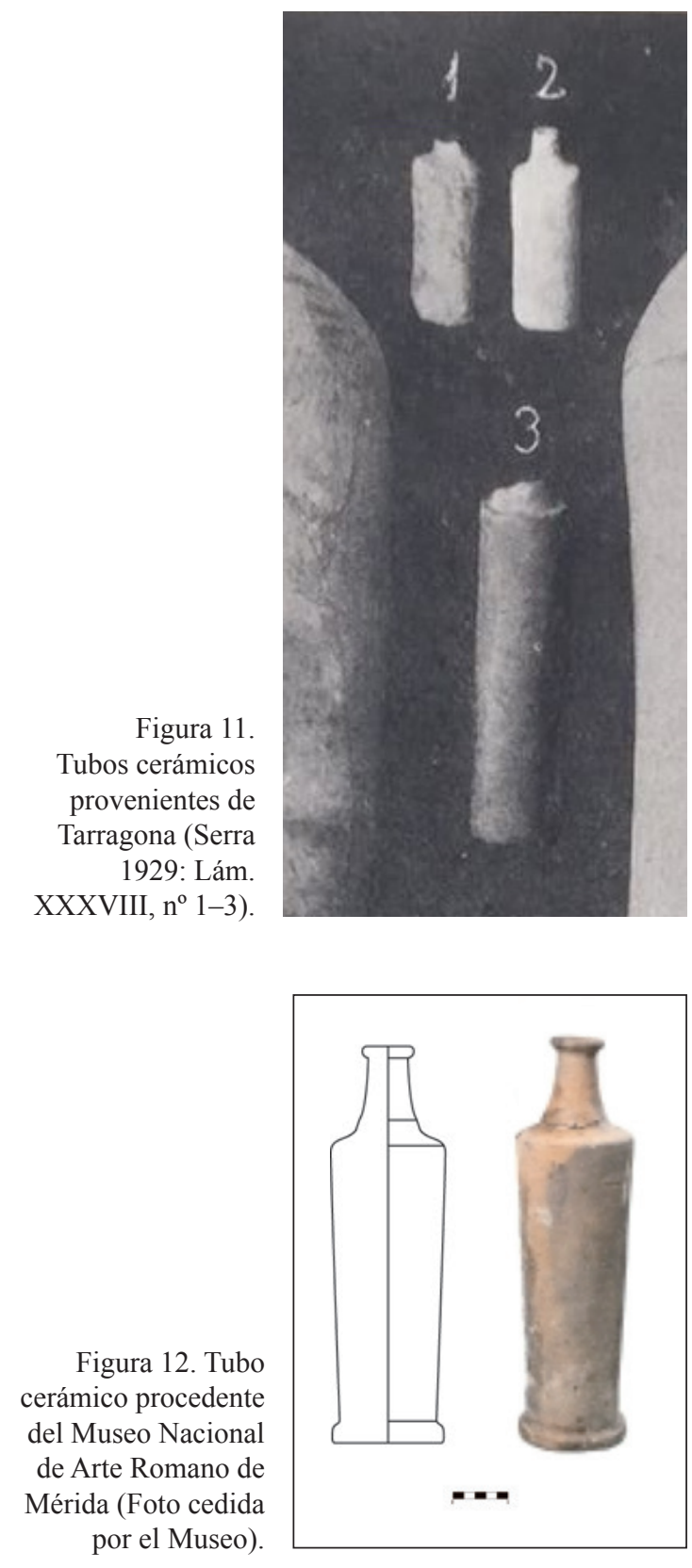

De los 19 ejemplos registrados, 7 son interpretados como tubos para libaciones y provienen de contextos funerarios. Del resto, 5 proceden de la carretera de circunvalación de Mérida, para la cual no existe un expediente de registro y se desconoce su autorización, tratándose de intervenciones antiguas. Los tubos presentan una forma cilíndrica, estrechándose en uno de sus extremos para conformar un segmento, también tubular, pero de menor diámetro externo. Las dimensiones máximas de los ejemplares conservados 
completos son de $35 \mathrm{~cm}$ de longitud y $9 \mathrm{~cm}$ de diámetro, realizados en arcilla de color rojiza. Debido a la escasez de datos y falta de contexto arqueológico no podemos determinar cuál sería la funcionalidad de estos tubos, pero teniendo en cuenta su gran tamaño, creemos prudente descartarlos como tubos cerámicos para bóvedas.

El origen de los tubos cerámicos restantes, de los que presentamos sus datos para que puedan ser analizados, es el siguiente: teatro romano (uno incompleto: $15,5 \mathrm{~cm}$ por $8 \mathrm{~cm}$ ), corchera extremeña (uno incompleto: $30 \mathrm{~cm}$ por $8,6 \mathrm{~cm}$ ), almacén de la alcazaba (dos incompletos: $20 \mathrm{~cm}$ por $10 \mathrm{~cm}$ ), vertedero en la zona sur de Mérida (completo: $32,5 \mathrm{~cm}$ por 10,5 cm), Solar de Torres (vinculado a un acueducto, incompleto: 26,5 $\mathrm{cm}$ por $13 \mathrm{~cm}$ ) y Casa del Anfiteatro (incompleto: 22 $\mathrm{cm}$ por $7 \mathrm{~cm})$.

En estos casos, y atendiendo al reducido número de tubos contabilizado y su gran tamaño, descartamos la construcción de bóvedas con tubos cerámicos para las piezas anotadas en el registro del Museo Nacional de Arte Romano de Mérida, sin entrar a juzgar cuál sería su función original, difícil de determinar ante la ausencia de contextos.

\subsubsection{Tubos cerámicos para bóvedas en contextos secundarios}

No todos los tubos cerámicos para bóvedas aparecen documentados en contextos originarios de uso, incluso algunos de ellos, aun habiéndolo estado, lo han perdido en el momento de su excavación, debido a la metodología de la misma.

Un ejemplo de contextos secundarios de estos tubos son los recuperados a través de la arqueología subacuática, provenientes de pecios hundidos en las costas hispanas. Los estudiados por Lancaster son tres y aparecen representados en su mapa de distribución (Lancaster 2015: fig. 66): Escolletes B, en Murcia (Cerezo 2015: $n^{\circ}$ 11, fig. 10), Cabo Blanco y Cabo de Moro Boti A, ambos en Mallorca (Veny 1979: 465-488). Sin embargo, estos casos quedan al margen de la problemática planteada en este artículo.

Probablemente no sean estos todos los enclaves donde se realizasen cubiertas abovedadas con tubos cerámicos, sin embargo, la ausencia en las publicaciones de estos materiales cerámicos y su presencia de forma aislada en algunas colecciones museográficas impiden ampliar el mapa de distribución que aquí presentamos.

\section{CONTEXTUALIZANDO LA PRESENCIA DE TUBI FITTILI EN HISPANIA: INFLUENCIAS EXÓGENAS EN LA TRANSMISIÓN DEL SISTEMA CONSTRUCTIVO}

Los interrogantes que nos planteamos vienen determinados, en primer lugar, por el reducido número de lugares donde se documenta su construcción en Hispania, por lo que creemos necesario observar si su producción sigue un patrón determinado, o por el contrario, su forma se adapta a las exigencias de los espacios que van a cubrir. Por otro lado, la cronología de su utilización se extiende desde mediados del siglo II a.C. hasta el siglo IV d.C., siendo necesario establecer o desestimar un vínculo entre los primeros ejemplares republicanos y aquellos tardorromanos, estableciendo las posibles influencias de su implantación. Además, en el norte de África su utilización es predominante en espacios termales, jugando un importante papel en la transmisión e innovación tecnológica (Lancaster 2015: 193-195), por lo que resulta decisivo conocer los espacios que cubrían.

Existen dos tipos diferenciados de tubos cerámicos en Hispania: el primero, documentado en Cabrera de Mar (1), se correspondería con la forma bullet-shaped tube (Lancaster 2015: 100-106), con una cronología de mediados del siglo II a.C., directamente relacionado con las innovaciones tecnológicas producidas anteriormente en Morgantina. Lucore apunta que no sería una coincidencia la transferencia de esta tecnología a suelo hispano y relaciona su presencia con soldados mercenarios (Lucore 2009: n. 18). Pero las termas republicanas de Cabrera de Mar suponen un ejemplo de sincretismo cultural y tecnológico, ya que nos encontraríamos ante un complejo termal de tipología itálica -Martín precisa que es campana (Martín 2000: 161)-, pero con una peculiaridad añadida al propio carácter innovador de la construcción de las cubiertas con tubos cerámicos, y es que sobre uno de ellos (7.10, numeración aportada por la publicación original) se ha documentado la existencia de un esgrafiado con signos ibéricos realizado antes de la cocción, que según sus investigadores, podría identificar al productor de estos tubos, de origen indígena (Sinner y Ferrer 2016: 209, 215, 219, fig. 9, fig. 13). Estamos, por tanto, ante una simbiosis en la que se presentan modelos edilicios itálicos pero cuyos materiales de construcción estarían producidos por artesanos de origen ibérico, y donde la procedencia más próxima para esta tipología de cubierta se localiza en la ciudad griega de Morgantina. Se trataría, de este modo, de una producción para un uso concreto 
(Lancaster 2015: 102-105) y para ello realizaron un encargo especial a los alfareros indígenas situados en el oppidum de Burriac.

El segundo de los tipos sería el denominado terracotta vaulting tube with nozzle (Lancaster 2015: 106108, 115-118), caracterizado por su forma de botella abierta en su base y con el extremo opuesto apuntado para facilitar el ensamblaje entre tubos. Este tipo es el documentado en Complutum (2), en la villa de Rabaçal (3) y en las villas de la vega granadina -Vergeles (4), Salar (5) y Las Gabias (7)-. Sus dimensiones oscilan entre los $26 \mathrm{~cm}$ de los documentados en la Casa de Hippolytus (2) y los $16 \mathrm{~cm}$ de los tubos de la villa de Salar (5); sus diámetros varían de 10,6 cm (Casa de Hippolytus) a 6-7 cm en la vega de Granada, lo que coincidiría con la media de los tubos norteafricanos (Lancaster 2015: 107). El reducido número de tubos documentados no nos permite hacer una lectura en detalle de la variedad de estos; además, Storz estableció que su tamaño tampoco tenía que estar asociado con el espacio que iban a cubrir (Storz 1994: 29-31). Pero sí debemos establecer que sus dimensiones siguen la tónica de los tubos cerámicos del norte de África, que comienzan a desarrollarse desde el siglo II d.C.

Los dos tipos de tubos cerámicos que acabamos de describir están relacionados con contextos y procesos históricos diferentes, no pudiendo establecerse una relación cronológica ni transferencia tecnológica entre ambos, separados entre cinco y seis siglos. De hecho, este vacío no es exclusivo de la península ibérica, sino que se aprecia en el resto del territorio bajo dominio romano. Storz (1994: 4-5) y Wilson (1992: 107-108) proponen que esta técnica tendría su origen en el uso de tubos para la construcción de la cámara de cocción de los hornos. Sin embargo, las evidencias arqueológicas documentadas hasta el momento no sostienen esta afirmación. Asimismo, no se han observado hornos con este tipo de bóveda en los alfares hispanorromanos.

En cuanto la influencia norteafricana en la introducción de tubos cerámicos a partir del siglo III d.C., esta parece confirmada. En este sentido, en el análisis de la Casa de Hippolytus, un aspecto que reclama nuestra atención son los elementos decorativos de este edificio, tanto sus mosaicos como sus pinturas. Dentro de los variados mosaicos que pavimentaron algunas de sus principales salas, destaca aquel que da nombre al conjunto, el mosaico de la sala central/frigidarium, donde aparece la inscripción referida a Hippolytus. No es nuestro objetivo realizar una descripción ni un análisis pormenorizado de este mosaico, ampliamente estudiado, cuyo emblema representa una escena de pesca con fauna marina y pescadores (Rascón et al. 1995-97 [1998]: 39-62; Gómez 2001: 219-220). Sí queremos detenernos en los paralelos y origen de este motivo decorativo, que se inicia en el siglo II d.C. en el África Proconsular, teniendo su máximo desarrollo en el siglo III d.C., con perduraciones hasta el siglo IV, incluso VI (Rascón et al. 1995-97 [1998]: 52), coincidiendo, por tanto, con el surgimiento y desarrollo de la técnica edilicia de construcción de bóvedas con tubos cerámicos en la misma región geográfica (Wilson 1992: 104-105 y 113; Lancaster 2015: 106-122).

Ante esta evidencia, hemos procedido a confrontar los paralelos ofrecidos para el emblema de la escena de pesca (Rascón et al. 1995-97 [1998]: 52-54) con la completa base de datos de Lancaster (2015). El resultado es que en todos los lugares con paralelos hallados para el emblema del mosaico de la Casa de Hippolytus en el norte de África existen evidencias de tubos cerámicos y construcción de bóvedas con esta técnica (Hippo Regius, Thuburbo Maius, Althiburos, Dougga, Djemila, Cartago, Sousse, Uthina y Bulla Regia). Igual ocurre con la decoración pictórica de la Casa de Hippolytus, que ha sido datada entre los siglos III-IV d.C., con repertorios norteafricanos.

El estudio del emblema de la Casa de Hippolytus concluye que es muy probable que este mosaico fuese realizado por artesanos norteafricanos, hipótesis que se vería reforzada por la presencia de material tunecino importado en la realización de algunas teselas de color verde empleadas en los peces (Rascón et al. 1995-97 [1998]: 55). En cuanto a la inscripción del mosaico que hace referencia a Hippolytus (ANNIORVM (hedera) HIPPOLYTVS TESSELLAV[IT]) fue reinterpretada por Gómez Pallarés (1998-1999 [2001]: 219-220) proponiendo como traducción: «(pavimento) de los Anios. Hipólito lo ha teselado» (Gómez 2001: 220), por lo que establece una relación contractual en la cual Hipólito, como artesano, realiza el mosaico por encargo de los Anios. Esta posibilidad de la actuación de musivarios africanos en la península ibérica durante el siglo IV ya había sido enunciada muchos años antes por Katherine Dunbabin (1978: 268).

Ante los datos, paralelos estilísticos y conexiones evidentes con el norte de África de los artesanos que realizaron el mosaico de la escena de la pesca de la Casa de Hippolytus, consideremos que este grupo de trabajadores especializados no solo aportó los cartones, técnica y materiales para la realización de los mosaicos y las pinturas murales, sino que pudieron ser también los transmisores de la tecnología utilizada para la construcción de la sala abovedada con tubos cerámicos, 
técnica edilicia que, coetáneamente, estaba teniendo su máximo desarrollo en el África Proconsular.

Del mismo modo, creemos pertinente establecer una conexión o influencia desde el ámbito norteafricano en la villa de Salar. Las razones para esgrimir este argumento se relacionan nuevamente con los motivos decorativos figurados de los mosaicos. Aunque las escenas de thiasos marino son muy frecuentes en la Antigüedad, como apunta Neira (1994: 1259-1278), son especialmente representativas en África del Norte, con patrones que se repiten en suelo hispano (Álvarez 1997: 40; Dunbabin 1978: 219; Neira 1997: 400). Por otro lado, los ejemplos de la villa de Salar se alejan de la tónica predominante en los motivos musivos de la vega granadina, lo que ha llevado a Marín Díaz a buscar las influencias de éstos en la Baetica Occidental (Marín 2016: 438-439) y adscribirlos a lo que se ha denominado "Escuela del Guadalquivir" (Mañas 2008: 612-614; 2011: 635-641), que si bien comienza con una marcada influencia itálica, hacia el siglo III d.C. y coincidiendo por tanto con la cronología del mosaico salareño, modifica dicha influencia e inicia una tendencia inspirada en los nuevos diseños que se están produciendo en el norte de África. Por tanto, la villa de Salar quedaría más en la órbita de ciudades como Antikaria (Antequera) o Astigi (Écija), volcada y comunicada con ellas a través de la vía de comunicación que supone el río Genil, que llega hasta la Granada romana (Gozalbes 1986: 195-196), y por la que debieron circular dichas influencias estilísticas.

Muy poco podemos aportar sobre la función de las estancias abovedadas con tubos cerámicos en Hispania. Tan solo disponemos para ello de la controvertida información aportada por la Casa de Hippolytus, donde el espacio cubierto podría estar vinculado a un complejo termal, y la villa de los Vergeles (Granada), donde se emplearían en una sala de representación absidada. Desconocemos por el momento la funcionalidad de la sala abovedada de la villa de Salar (Granada), aunque constatamos también la presencia de estos tubos en la zona del ninfeo, y por tanto, de nuevo, en un espacio de representación. En el caso de la villa de Las Gabias (Granada), estos objetos están descontextualizados.

En cuanto a la fabricación de los tubos, ya hemos hecho referencia al excepcional caso de las termas de Cabrera de Mar. Para el resto de manufacturas, desconocemos su lugar de producción pero, pese a su influencia norteafricana, descartamos que sean objeto de comercio e importación. El elevado número de tubos necesarios para construir una sola de estas bóvedas haría económicamente costoso el proyecto. Si bien es cierto que se han encontrado algunos de estos tubos en pecios hundidos en el Mediterráneo Occidental, su cargamento podría deberse a los materiales de relleno que son necesarios en los navíos como contrapeso (Lancaster 2015: 115). Consideramos que estas producciones se realizarían en hornos próximos a su lugar de utilización, al igual que otras fabricaciones latericias utilizadas en la construcción. Es ampliamente sabido que las villas disponían de sus propios hornos para aprovisionarse de materiales de construcción; sin embargo, entre los ejemplos estudiados, ninguno ha sido constatado en una zona de alfar. Por otro lado, la reducción de su tamaño en época bajoimperial y la simplicidad de su forma, hecha a torno, facilitaría su elaboración in situ.

\section{LAS VILLAS CON BÓVEDAS DE TUBI FITTILI EN LA VEGA DE GRANADA: ASPECTOS SOCIOECONÓMICOS DE LA APARICIÓN DE ESTA TÉCNICA EDILICIA EN CONTEXTOS RURALES}

El número de enclaves donde constatamos la construcción de estancias abovedadas con tubos cerámicos es tan reducido en Hispania, que la concentración de al menos tres de estos ejemplos en la Vega de Granada no debe ser una casualidad. La edificación de espacios abovedados en las villas de los Vergeles, Las Gabias y Salar podría estar relacionada con la existencia de un taller o cuadrilla de artesanos que conocían esta peculiar técnica constructiva y que trabajaron en el ager de las ciudades de la vega del Genil.

La existencia de estos talleres itinerantes en el mundo romano está sobradamente atestiguada, especialmente aquellos procedentes del ámbito itálico que se instalan en suelo hispano, dedicados, entre otras actividades, a la edilicia pública (Mar et al. 2015: 128-129), la escultura u otros trabajos artesanales. Sin embargo, el conocimiento acerca de estos talleres se centra, sobre todo, en actividades edilicias de carácter público o aquellas atestiguadas en las fuentes clásicas o la epigrafía, siendo mucho más complejo realizar aproximaciones de carácter local o de regiones provinciales de periferia, como sería el caso de la vega granadina. En todo caso, y como ya hemos indicado anteriormente, algunos investigadores ya han propuesto la posible llegada de artistas y artesanos norteafricanos a la península ibérica (Dunbabin 1978: 219-220), a partir de las evidentes conexiones e influencias que se observan en los mosaicos de ambas regiones (Dunbabin 1978: 268; Blázquez 1991; Blázquez et al. 1991; Álvarez 1997). 
Disponemos de un trabajo actualizado sobre los talleres musivos granadinos que concluye que, para el caso de la villa romana de Salar, no se puede descartar la llegada de talleres foráneos de la Bética Occidental, debido a las fuertes influencias exógenas de los motivos figurados de sus mosaicos, así como por la cuidada técnica de su trabajo (Marín 2016: 406, 420). Por otro lado, no solo se pueden constatar estas influencias alógenas, sino que podría existir una relación entre las villas de Las Gabias y Salar, ya que en ambas se ha documentado la utilización de opera sectilia parietales. En este caso son mayores las reservas que se plantean, ya que aunque los motivos decorativos vegetales son muy próximos, estos son comunes en todo el territorio hispano en la decoración con interrasum, y la técnica de labrado de ambas es distinta (Marín 2016: 421, 442-443).

Uno de los mayores problemas que se plantea en el análisis de estas villas viene determinado por el establecimiento de sus cronologías y fases constructivas. En muchas ocasiones, el estudio de los materiales ha quedado relegado a un segundo plano, frente a la monumentalidad de los hallazgos; no obstante, podemos concretar sus principales fases edilicias. La villa romana de los Vergeles tiene un período de reformas en el siglo IV d.C., momento en el que se construyeron las salas absidadas donde se documentaron los derrumbes de tubos cerámicos. Por otro lado, la villa de Las Gabias vivió un período de remodelación en época bajo imperial (finales del siglo IV-V d.C.), momento en el que se documentan el uso del opus sectile en el criptopórtico y los mosaicos encontrados en el Camino Hondo (Marín 2016: 180), donde aparecieron los tubos cerámicos. Finalmente, en Salar, se aprecia un proceso de monumentalización en el siglo III d.C., con remodelaciones en los siglos IV-V d.C., constatando el abandono de la sala abovedada en el siglo VI d.C. (Moreno et al. 2017). Con estos datos, no sería descabellado considerar que existiese un maestro de obras o arquitecto trabajando en el ager de las ciudades de la vega del Genil, durante aproximadamente una generación, que conocía la técnica de la construcción de bóvedas con tubos cerámicos y que trabajaba en estrecha relación con otras cuadrillas de artesanos dedicadas a otras actividades edilicias (como mosaiquistas, estucadores, etc.).

Pero nuestra hipótesis sigue manteniendo la duda de por qué elegir esta técnica de construcción de bóvedas, frente, por ejemplo, a otras más comunes que necesitan cimbras de madera para su construcción. En este sentido, es relevante el trabajo de Wilson analizando los factores necesarios para el surgimiento de esta técnica constructiva. Observa una relación con la construcción de las bóvedas de las cámaras de cocción de los hornos -que ya hemos desestimado para Hispania anteriormente-, la escasez de madera o la reducción del peso de la bóveda - poniendo ambas en entredicho- (Wilson 1992: 107-109); por eso, sobre todas ellas, considera que el desarrollo de esta técnica edilicia se debe más a un factor personal del arquitecto que conoce la técnica y decide emplearla (Wilson 1992: 109; Lancaster 2015: 118). Esto justificaría que en la Vega de Granada, en torno al siglo IV d.C., existiesen uno o varios arquitectos que, por influencia, directa o indirecta, del norte de África, conociesen esta técnica y la aplicasen en la construcción de bóvedas de las villas granadinas.

El debate sobre por qué se desarrolla esta técnica, concretamente en el norte de África, y especialmente a partir del siglo III d.C., ha generado diferentes hipótesis. Lancaster las sintetiza en su trabajo, recogiendo las opiniones de otros investigadores (Lancaster 2015: 115-118). Uno de los aspectos más destacados es que no era necesario realizar cimbras en madera sobre las que construir las bóvedas, porque los tubos son más resistentes para soportar y distribuir los pesos generados, ya que los tubos eran sustentos permanentes. Tradicionalmente se mantenía que su uso en las bóvedas suponía una reducción de su peso, algo que se ha demostrado no sería determinante para su elección (Lancaster 2015: 116). Finalmente, se asociaban con la falta de disponibilidad de madera, razón que tampoco sería clave en la Vega de Granada. Por ello consideramos que la elección de esta solución de cubierta abovedada no viene motivada por una necesidad, sino más bien por una oportunidad, la de su conocimiento por parte de los artífices que la aplicaron en las villas granadinas; y que además, atendiendo a su desarrollo en el norte de África y a esa posible llegada de artistas y artesanos desde dicha región hasta la península ibérica, la cuadrilla especializada que trabajaba en la Vega granadina podría, o bien ser norteafricana, emigrada en busca de nuevas oportunidades laborales, o bien haber sido formada por alguno de dichos emigrantes.

Ello no suponía que se dejasen de construir otro tipo de cubiertas, como podemos comprobar por ejemplo en la villa de Salar, en cuyo CE-03 parece que se emplearon tanto la cubierta abovedada con tubos cerámicos para la parte central de la estancia, como una cubierta más simple, a un agua con tegulae, en el cubículo sur. Por otro lado, no podemos establecer con certitud por qué estos constructores conocían el uso de tubos cerámicos para bóvedas o cuál sería su relación con el norte de África, donde evidentemente se desarrollaron, aunque sí creemos posible desestimar que su presencia en 
la Vega de Granada se deba a un factor militar, como apunta Lancaster para otras regiones del imperio (Lancaster 2015: 108-112), pudiendo entroncar, no obstante, con el crecimiento económico y las relaciones comerciales que se desarrollan desde el siglo III d.C. en esta provincia africana (Lancaster 2012: 145-160).

\section{CONCLUSIONES}

La utilización de tubos cerámicos para la construcción de bóvedas fue una técnica escasamente difundida, como ya apuntábamos, en la arquitectura hispanorromana. Ante el descubrimiento de la utilización de esta técnica en la villa de Salar, creímos necesario realizar una profunda revisión de los casos documentados hasta el momento en la península ibérica. De este trabajo hemos concluido que su mapa de distribución es muy diferente al anteriormente presentado (Lancaster 2015: 101, fig. 66), ya que solo podemos constatar con evidencias arqueológicas la construcción de espacios abovedados en Cabrera de Mar - un caso particular, por su cronología-, y, en época tardorromana, en la casa de Hippolytus en Complutum, la villa romana de Rabaçal, y en las villas de la Vega de Granada (Vergeles, Las Gabias y Salar). Por ello, observamos que los constructores de bóvedas hispanos debieron preferir otras técnicas de las que, probablemente, tenían más conocimiento.

De esta manera, el mapa de distribución quedaría dividido en dos momentos. Uno, inicial, a mediados del siglo II a.C., cuando se documenta la construcción de las salas abovedadas de las termas de Cabrera de Mar. A partir de esta fecha, la transferencia del conocimiento de esa técnica constructiva quedaría olvidada en la península ibérica, no habiéndose documentado su empleo, en esta cronología y tipología, en otros yacimientos hispanos. Además, Cabrera de Mar es un caso excepcional, no solo por la aparición de los tubos cerámicos, sino por su contexto histórico y cultural, reflejo de los movimientos de personas e ideas en el Mediterráneo occidental; y es que en un mismo edificio se constata una tipología netamente itálica en el diseño de los baños, con el uso de estos tubos cerámicos, cuyo paralelo más próximo se encuentra en la ciudad griega de Morgantina (Sicilia), pero que además fueron realizados por artesanos iberos, a tenor de las marcas que se han documentado en algunos de ellos.

El segundo momento de utilización en Hispania de este sistema constructivo, si bien con una nueva tipología de tubos cerámicos, se produce ya en los siglos III-IV d.C., con una clara influencia norteafricana.
Lancaster sugiere que un factor decisivo para la proliferación de esta técnica en el norte de África es el geológico -como ya defendió Arslan (1965: 45-52)-, asociando su desarrollo a la existencia de sulfato de calcio (yeso) que se utilizaba para fraguar la unión entre los tubos y, de esta manera, no tener que utilizar armazones de madera en la construcción de la bóveda (Lancaster 2015: 194-195). Si bien coincidimos en la ventaja de no necesitar cimbras, no creemos que para la península ibérica el contexto geológico de presencia/ ausencia de yeso sea decisivo, ya que España es también rica en sulfato de calcio (Regueiro y Calvo 1997: 563-569) y la transferencia de esta tecnología fue muy reducida. Por ello, y ante la documentación de esta técnica solamente en Complutum, Rabaçal y el caso particular de la Vega de Granada, consideramos que el factor determinante de la transferencia del conocimiento de la construcción de bóvedas con tubos cerámicos fue la presencia de cuadrillas de artesanos y trabajadores que habían tenido algún contacto, directo o indirecto, con el norte de África - que queda atestiguado en otros ámbitos de la edilicia, como sería el caso de los mosaicos-, descartando la presencia militar como un factor relacionado con la transmisión de esta técnica.

Finalmente, creemos que se deben realizar más estudios y publicaciones sobre los contextos arqueológicos y los materiales constructivos que aparecen en ellos, pues pensamos que probablemente existan más ejemplos de bóvedas construidas con tubos cerámicos en Hispania, pero que han pasado desapercibidos debido a su multifuncionalidad, siendo adscritos a otros usos.

\section{Agradecimientos}

El presente trabajo ha contado con el soporte del Proyecto de I+D "Producción y adquisición de cerámicas finas en el proceso de configuración de las comunidades cívicas de la Bética y la Hispania Meridional durante el Alto Imperio Romano (HAR2016-75843-P)". Ministerio de Ciencia e Innovación del Gobierno de España.

Este trabajo se enmarca en el Proyecto de Actuación Puntual "Sondeos en la villa romana de la Revuelta de Enciso en Salar (Granada)", con n ${ }^{\circ}$ Expte 011/PU/GR/ 16.

Queremos transmitir nuestro más sincero agradecimiento al Ayuntamiento de Salar (Granada) por el soporte económico prestado para la realización de las sucesivas campañas de excavación arqueológica, desde el año 2016, así como a los museos, instituciones e investigadores que nos han prestado su colaboración para este trabajo. 


\section{BIBLIOGRAFÍA}

Álvarez Martínez, A. (1997): “La influencia africana en el mosaico hispanorromano: algunas consideraciones". Anas 10: 39-50.

Arce Martínez, J. (2010): “El complejo residencial tardorromano de Cercadilla (Corduba)", en D. Vaquerizo Gil (ed.), Las áreas suburbanas en la ciudad histórica. Topografía, usos, función: 397-412. Córdoba, Universidad de Córdoba.

Arslan, E. A. (1965): “Osservazioni sull'impiego e la diffusione delle volte sottili in tubi fittili". Bollettino d'Arte ser. 5, 50: 45-52.

Berges Soriano, P. M. (1977): Nuevo informe sobre Els Munts. Estudis Altafullencs, 1, Centre d'Estudis d'Altafulla: 27-47.

Blázquez Martínez, J. M. (1991): “Aspectos comunes de los mosaicos de Cerdeña, África y España”, en L'Africa Romana VIII, 2: 811-926. Cagliari (1990), Sassari, Gallizi.

Blázquez, J. M.; López, G.; García-Gelabert, M. P. y Neira, M. L. (1990): "Influjos africanos en los mosaicos hispanos", en L'Africa Romana VII, 2: 673699. Sassari (1989), Sassari, Gallizi.

Bound, M. (1987): "Tubi Fittili (Vaulting Tubes) from the Sea. The Roman Wreck at Punta del Fenaio, Island of Giglio". Internacional Journal of Nautical Archaeology 6.3: 187-200.

https://doi.org/10.1111/j.1095-9270.1987.tb00586.x

Bovini, G. (1960): “L'impiego dei tubi fittili nelle volte degli edifici di culto ravennati”. Felix Ravenna 30: 78-99.

Cabré Aguiló, J. (1922): "Monumento cristiano-bizantino de Gabia la Grande (Granada). Memoria de la inspección y las excavaciones realizadas". Memorias de la Junta Superior de Excavaciones y Antigüedades, 55. Madrid, Tipografía de la Revista de Archivos, Bibliotecas y Museos.

Cerezo Andreo, F. (2015): "La colección material del yacimiento subacuático de Escolletes. Arqueología náutica y dinámicas y comerciales en el sureste ibérico en época bajo imperial", en A. Fernández Díaz (ed.), I Encuentro de jóvenes investigadores en arqueología de la Región de Murcia: de la Arqueología Prehistórica a la Arqueología Industrial: 449496. Murcia, Universidad de Murcia.

Corzo Sánchez, R. (2009): “El episcopium de Cercadilla y la arquitectura cristiana hispánica". Boletín de la Real Academia de Córdoba, de Ciencias, Bellas Letras y Nobles Artes Julio-Diciembre 2009, LXXXIX, 157: 111-131.
Dodge, H. (1989): "Building Material, 1. Terracotta Vaulting Tubes (Tubi Fittili)", en M. Fulford y M. Hall (eds.), Excavations at Sabratha 1948-1951, 2.1 The Finds: 249-251. Tripoli, Society for Libyan Studies.

Dunbabin, K.M.D. (1978): The Mosaics of Roman North Africa. Studies in Iconography and Patronage. Oxford Monographs on Classical Archaeology. Oxford, Clarendon Press.

Durán, R. (1998): “Catálogo, no 5, Complutum, Casa de Hippolytus", en S. Rascón Marqués (ed.), Complutum. Roma en el interior de la Península Ibérica [catálogo de la exposición celebrada en] Capilla del Oidor: 208. Madrid, Fundación Caja de Madrid.

Fernández Castro, M. C. (1978): “Aspectos arquitectónicos y musivarios de las villas romanas de Andalucía”, en Actas I Congreso Historia de Andalucía. Fuentes y metodología. Andalucía en la Antigüedad: 327. Córdoba (1976), Córdoba, Monte de Piedad y Caja de Ahorros de Córdoba.

Fresneda, E.; Toro, I.; Peña, J.M.; Gómez, R. y López, M. (1993): "Excavación arqueológica de emergencia en la villa romana de la calle Primavera (Granada)". Anuario Arqueológico de Andalucía 1991, III: 149-156. Sevilla, Junta de Andalucía.

García Entero, V. (2004): "Nueva propuesta interpretativa de la llamada Casa de Hippolytus de Complutum (Alcalá de Henares, Madrid). Un complejo termal suburbano". Archivo Español de Arqueología 77: 143-158. https://doi.org/10.3989/aespa.2004. v77.94

Gómez Pallarés, J. (1998-1999 [2001]): “Apostillas al estudio de la inscripción musiva de Hippolytus (Complutum, Alcalá de Henares, Madrid)". Lucentum XVII-XVIII: 219-220. https://doi. org/10.14198/LVCENTVM1998-1999.17-18.12

Gozalbes Cravioto, C. (1986): Las vías romanas de Málaga. Madrid, Turner.

González Martín, C. (2014a): Informe preliminar de la I.A.P. en la villa romana de Salar. Depositado en la Delegación Provincial de Cultura de Granada, Granada.

González Martín, C. (2014b): "Poblamiento y territorio en el curso medio del Genil en época romana: nuevas aportaciones arqueológicas. La villa romana de Salar". Florentia Iliberritana 25: 157-194.

González, C. y El-Amrany, T. (2013): Guía Arqueológica. Villa romana de Salar. Granada, Diputación de Granada.

Hidalgo Prieto, R. (1996): Espacio público y espacio privado en el conjunto palatino de Cercadilla 
(Córdoba): el aula central y las termas. Sevilla, Junta de Andalucía.

Hidalgo Prieto, R. (2014): “¿Fue Cercadilla una villa? El problema de la función del complejo de Cercadilla en Corduba". Archivo Español de Arqueología 87: 217-241. https://doi.org/10.3989/ aespa.087.014.014

Lancaster, L. (2012): “Ash Mortar and Vaulting Tubes: Agricultural Production and the Building Industry in North Africa", en S. Camporeale, H. Dessales y A. Pizzo (eds.), Arqueología de la construcción III. Los procesos constructivos en el mundo romano: la economía de las obras. Anejos de Archivo Español de Arqueología, LXIV: 45-160. Mérida, Consejo Superior de Investigaciones Científicas; Instituto de Arqueología de Mérida.

Lancaster, L. (2015): Innovative Vaulting in the Architecture of the Roman Empire. 1st to 4th centuries $C E$. Cambridge, Cambridge University Press.

Lézine, A. (1954): "Les voûtes romaines à tubes emboités et les croisées d'ogive de Bulla Regia". Karthago 5: 168-181.

López Vilar, J. (1993): "Les termes inferiors de la vil·la romana dels Munts". Documents d'Arqueologia Clàssica 0: 56-79.

López Cuevillas, F. (1953): "Restos romanos en la Limia". Cuadernos de Estudios Gallegos VIII: 437-438.

Lucore, S. K. (2009): “Archimedes, the North Baths at Morgantina, and early devolopments in vaulted construction", en C. Kosso y A. Scott (eds.), The nature and function of water, baths, bathing, and hygiene from antiquity through the Renaissance. Technology and change in history v. 11: 43-59. Leiden, Boston, Brill.

Lucore, S. K. (2013): “Archimede e le Terme Nord di Morgantina”, en B. Basile; D. Di Pasquale; C. Parisi Presicce; J. Reen y P. Galluzzi (eds.), Archimede. Arte e scienze dell'invenzione, Museo Galileo: 52-55. Firenze, Giunti.

Mañas Romero, I. (2008): Pavimentos decorativos de Itálica (Santiponce, Sevilla). Tesis doctoral, Universidad Complutense de Madrid. Inédita.

Mañas Romero, I. (2011): "La creación de la escuela musivaria del Guadalquivir: modelos itálicos e interpretación regional", en T. Nogales e I. Rodá (eds.), Roma y las provincias: modelos y difusión II: 635-641. Italia, L'Erma di Bretschneider.

Mar, R.; Ruiz de Arbulo, J; Vivó, D. y Beltrán, J.A. (2015): Tarraco. Arquitectura y urbanismo de una capital provincial romana. Volumen II. La ciudad imperial. Documents d'Arqueologia Clàssica 6. Tarragona, Institut Català d'Arqueologia Clàssica.

Marfil Ruiz, P. (2001): “Córdoba de Teodosio a Abd alRahmán III”, en Visigodos y Omeyas, un debate entre la Antigüedad tardía y la Alta Edad Media: 117142. Mérida (1999), Mérida, Consejo Superior de Investigaciones Científicas.

Marfil Ruiz, P. (2010-2011): "El complejo cristiano de Cercadilla". Anales de Arqueología Cordobesa 21-22: 241-252. https://doi.org/10.21071/aac. v0i0.6461

Marín Díaz, P. (2011): "Una aproximación a la musivaria tardoantigua en Iliberis. Los mosaicos de la villa de los Vergeles (Granada)". Arqueología y territorio 8: 173-186.

Marfil Ruiz, P. (2016): Otium, salubritas, amoenitas. Decoraciones musivas y pictóricas romanas en la Vega de Granada. Tesis Doctoral, Universidad de Granada. Inédita.

Martín Menéndez, A. (2000): "Las termas republicanas de Cabrera de Mar (Maresme, Barcelona)", en C. Fernández Ochoa y V. García Entero (eds.), Termas romanas en el occidente del Imperio II (Gijón): 157-162. Gijón, VTP Editorial.

Mason, D. J. P. (1990): “The Use of Earthenware Tubes in Roman Vault Construction: An Example from Chester". Britannia 21: 215-222.

Monneret de Villard, U. (1924): "Sull'impiego di vasi e tubi fittili nella costruzione delle volte", en C. Hülsen; C. Cecchelli; G. Giovannoni; U. Monneret de Villard y A. Muñoz-Alonso (eds.), Sant'Agata dei Goti: 149-154. Roma, Sasaini.

Morín de Pablos, J. (ed.) (2014): Los paisajes culturales en el valle del Cigüela. Madrid, Auditores de Energía y Medio Ambiente S.A.

Moreno Alcaide, M.; Román Punzón, J.M. y Ruiz Montes, P. (e.p.): "Nuevo ejemplo del uso de tubi fittili en arquitectura hispanorromana: la sala abovedada de la villa romana de Salar (Granada)", en IV Congreso del SECAH-EX OFFICINA HISPANA. Valencia (2017).

Neira Jiménez, L. (1994): "Mosaicos romanos con nereidas y tritones. Su relación con el ambiente arquitectónico en el Norte de África y en Hispania”, en L'Africa romana. Atti del X convegno di studio: 1259-1278. Oristano (1992), Sassari, Editrice Archivio Fotografico Sardo.

Neira Jiménez, L. (1997): "Representaciones de nereidas. La pervivencia de algunas series tipológicas en los mosaicos romanos de la Antigüedad Tardía". 
Antigüedad y Cristianismo (La tradición en la Antigüedad Tardía) XIV: 373-402.

Oliver, M. y Gómez-Moreno, M. (1870): Informe sobre varias Antigüedades descubiertas en la Vega de esta ciudad. Granada, Imprenta D. Indalecio Ventura.

Otiña Hermoso, P. (2005): La vil·la romana dels Munts (Altafulla): Excavacions de Pedro Manuel Berges Soriano. Biblioteca Tarraco d'Arqueologia 1. Reus, Fundació Privada Liber.

Pareja, E. y Sotomayor, M. (1979): "El yacimiento romano de Gabia la Grande en Granada". Noticiario Arqueológico Hispánico 6: 423-440.

Pérez, C. y Toro, I. (1991): “Intervención arqueológica de urgencia en C/ Primavera, 22 (Los Vergeles, Granada)". Anuario Arqueológico de Andalucía 1989, III: 228-232.

Pessoa, M. (1998): Villa romana do Rabaçal. Un objecto de arte na Paisagem. Penela, Câmara municipal de Penela.

Pessoa, M. (2004): Catálogo: Espaço-Museu Villa romana do Rabaçal. Texto e concepção Miguel Pessoa y Lino Rodrigo. Penela, Câmara municipal de Penela.

Rascón Marqués, S. (ed.) (1998): Complutum. Roma en el interior de la Península Ibérica [catálogo de la exposición celebrada en] Capilla del Oidor. Madrid, Fundación Caja de Madrid.

Rascón Marqués, S. (2000): “La casa de Hippolytus y la recuperación del Patrimonio Arqueológico de Alcalá de Henares". Boletín de la Asociación Española de Archiveros, Bibliotecarios, Museólogos y Documentalistas 50, 2: 203-218.

Rascón Marqués, S. (2007): "La así llamada Casa de Hippolytus: la fundación de los Anios y la schola de una agrupación colegial de la ciudad romana de Complutum". Archivo Español de Archeología 80: 119-152. https://doi.org/10.3989/aespa.2007. v80.30

Rascón Marqués, S. (2016): “Casa de Hippolytus, Complutum (Alcalá de Henares, Madrid)", en O. Rodríguez Gutiérrez; N. Tran y B. Soler Huertas (eds.), Los espacios de reunión de las Asociaciones Romanas: diálogos desde la arqueología y la historia, en homenaje a Bertrand Goffaux: 395-401. Sevilla, Universidad de Sevilla.

Rascón, S. y Polo, J. (1996): "La casa de Hippolytus (Alcalá de Henares, Madrid): la schola de un colegium iuvenum complutense", en $V$ Encuentro de Historiadores del Valle del Henares: 61-77. Guadalajara (1996), Guadalajara, IMS.
Rascón, S.; Polo, J.; Gómez, J. y Méndez, A. (1995-97 [1998]): "Hippolytus: estudio de un nuevo mosaico del género de pesca y con inscripción procedente de Complutum, Alcalá de Henares, Madrid". Lucentum XIV-XVI: 39-62. http://dx.doi.org/10.14198/ LVCENTVM1995-1997.14-16.03

Regueiro, M. y Calvo, J.P. (1997): “El yeso. Geología y yacimientos en España". Boletín de la Sociedad Española de Cerámica y Vidrio. Dossier 36: 563-569.

Russo, E. (1996): "Sulla cupola di tubi fittili di S. Vitale di Ravenna". Rivista di Archeologia Cristiana 72: 285-329.

Scurati-Manzoni, P. (1997): "La volta in tubi fittili di Pompeii". Palladio 20: 9-18.

Serra Vilaró, J. (1929): "Excavaciones en la necrópolis romano-cristiana de Tarragona". Junta superior de excavaciones y antigüedades, Memoria 104 (1928, $\mathrm{n}^{\circ}$ 6). Madrid, Tipografía de la Revista de Archivos, Bibliotecas y Museos.

Shepherd, E J. (2014): "Una volta "sottile" nelle terme romane di Piazza della Signoria", en G. Baldelli G. y F. L. Schiavo (eds.), Amore per l'antico. Dal Tirreno all'Adriatico, dalla Preistoria al Medioevo e oltre. Studi di antichità in ricordo di Giuliano de Marinis 1: 257-265. Roma, Scienze e Lettere.

Sinner, A. y Ferrer, J. (2016): "Del oppidum de Burriac a las termas de Ca l'Arnau. Una aproximación a la lengua y a la identidad de los habitantes de Ilduro (Cabrera de Mar, Barcelona)". Archivo Español De Arqueología 89: 193-223. https://doi.org/10.3989/ aespa.089.016.010

Storz, S. (1994): Tonröhren im antiken Gewölbebau: Mit einer Rekonstruktion des Schalungstragwerkes für die Trompengewölbe der Kobbat Bent el Rey in Karthago. Deutsches Archäologisches Institut Rom. Sonderschriften Bd. 10. Mainz am Rhein, Philipp von Zabern.

Tomasello, F. (2005): "Volte "leggere" a tubi fittili. Tra Sicilia e Africa”. Sicilia Antiqua 2: 145-155.

Torrecilla Aznar, A. (1999): "Materiales de construcción en las termas de la Hispania romana, a propósito de los materiales hallados en la villa de El Saucedo (Talavera la Nueva, Toledo)", en Actas del XXIV Congreso Nacional de Arqueología vol. 4: 397-416. Cartagena (1997), Cartagena, Gobierno de la Región de Murcia, Instituto de Patrimonio Histórico.

Urbina, D. y Morín, J. (eds.) (2013): Excavaciones en Casas de Luján II. Balnea, alfares y almazaras en el territorio segobrigense. Memorias Arqueológicas 
de AUDEMA. Madrid, Auditores de Energía y Medio Ambiente S.A.

Urbina, D.; Urquijo, C. y Morín, J. (2013): “Unos baños altoimperiales en la villa romana de Casas de Luján, Segóbriga (Saelices, Cuenca)". Sagvntvm 45: 193208. https://doi.org/10.7203/SAGVNTVM.45.1970 Vann, R. (1993): "Vaulting Tubes from Caesarea Maritima". Israel Exploration Journal 43: 29-34.

Veny, C. (1979): "Nuevos materiales de Moro Boti". Trabajos de Prehistoria 36, 1: 465-488.
Verzone, P. (1938): "Le cupole di tubi fittili nel V e VI secolo in Italia", en Atti del I congreso nazionale di storia dell'architettura: 7-12. Florencia (1936), Florencia, Sansoni.

Wilson, R.J.A. (1992): "Terracotta vaulting tubes (tubi fittili): on their origin and distribution". Journal of Roman Archaeology 5: 97-129. https://doi. org/10.1017/S104775940001196X

Wilson, R.J.A. (2002): "Roman Vaulting Tubes (Tubi Fittili) from Chesters". Archaeologia Aeliana 30: 180-185. 